\title{
Contrasting Arene, Alkene, Diene, and Formaldehyde Hydrogenation in H-ZSM-5, H-SSZ-13, and H-SAPO-34 Zeolite Frameworks during MTO
}

\author{
Mykela DeLuca, Christina Janes, and David Hibbitts* \\ Department of Chemical Engineering, University of Florida, Gainesville, FL 32611 \\ *corresponding author email: hibbitts@che.ufl.edu
}

\begin{abstract}
Co-feeding $\mathrm{H}_{2}$ at high pressures increases zeolite catalyst lifetimes during methanol-to-olefin (MTO) reactions while maintaining high alkene-to-alkane ratios; however, the atomistic mechanisms and species hydrogenated by $\mathrm{H}_{2}$ co-feeds to prevent catalyst deactivation remain uncertain. This study uses periodic density functional theory (DFT) to examine hydrogenation mechanisms and rates of MTO product alkenes and species formed during MTO that have been linked to catalyst deactivation: $\mathrm{C}_{4}$ and $\mathrm{C}_{6}$ dienes, formaldehyde, and benzene. Hydrogenations of these species are examined in models of H-ZSM-5 (MFI framework), H-SSZ-13 and H-SAPO-34 (CHA framework). Single-step and two-step hydrogenation mechanisms occur with similar barriers for all reactants on all zeolites with $\mathrm{H}_{2}$ dissociation (hydride transfer) being the difficult part of these mechanisms. Hydrogenation barriers trend well with carbenium stabilities with products forming oxocarbeniums and allylic carbocations forming at higher rates than those proceeding via alkylcarbeniums. As such, dienes and formaldehyde are selectively hydrogenated during MTO compared to product alkenes, occurring with barriers $15-40 \mathrm{~kJ}^{\mathrm{mol}}{ }^{-1}$ lower than $\mathrm{C}_{2}-\mathrm{C}_{4}$ alkene hydrogenation, with diene hydrogenation $\sim 10 \mathrm{~kJ} \mathrm{~mol}^{-1}$ lower than formaldehyde hydrogenation. Butadiene hydrogenation is also facilitated by $\alpha, \delta$ protonation and hydridation schemes which form 2-butene as primary products, in contrast to $\alpha, \beta$ routes forming 1-butene-both routes occur via allylic carbocations indicating that carbocation stability is not the only driver towards selective diene hydrogenation. Barriers of hexadiene hydrogenation are lower than those of butadiene, indicating that longer carbon chains can stabilize the intermediate carbocations. Benzene, in contrast to dienes and formaldehyde, is hydrogenated with higher barriers than $\mathrm{C}_{2}-\mathrm{C}_{4}$ alkenes despite proceeding via stable benzenium cations because of the instability of the non-aromatic product. Hydrogenation barriers in H-SSZ-13 and H-ZSM-5 are within $12 \mathrm{~kJ}^{-1} \mathrm{~mol}^{-1}$ of one another indicating both demonstrate similar hydrogenation rates. Hydrogenation barriers in H-SAPO-34 are 12$38 \mathrm{~kJ} \mathrm{~mol}^{-1}$ higher than those in H-SSZ-13 (both CHA) and that zeotype also seems to favor formaldehyde hydrogenation over diene hydrogenation (in contrast to the aluminosilicates). $\mathrm{H}_{2} \mathrm{O}$ increases the efficacy of $\mathrm{H}_{2}$ co-feeds but does not directly assist in hydrogenation pathways; instead, it increases hydrogenation rates by increasing the concentration of surface protons through alkyl hydration reactions.
\end{abstract}

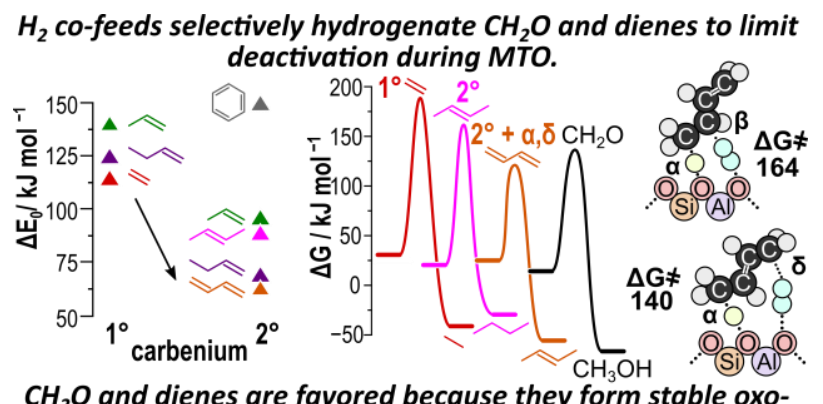

$\mathrm{CH}_{2} \mathrm{O}$ and dienes are favored because they form stable oxoand allylic carbenium ions and undergo $\alpha, \delta$ attack . 


\section{Introduction}

Zeolite-catalyzed methanol to olefins (MTO) produces primarily ethene and propene with some $\mathrm{C}_{4}$ alkenes and is a widely studied ${ }^{1-7}$ alternative route for producing light olefins. Zeolite catalysts, however, are susceptible to deactivation via the formation of large, polyaromatic species thus limiting their efficiency and requiring the use of recirculating fluidized bed reactors in industrial applications. ${ }^{8-13}$ Two complementary co-catalyzed cycles form products from methanol during MTO. ${ }^{14-19}$ Alkenes methylate and grow to a size capable of cracking into $\mathrm{C}_{3}-\mathrm{C}_{5}$ compounds in the olefin cycle. .17,20,21 These olefins can undergo hydride transfer reactions to form alkanes and dienes - either via alkene disproportionation ${ }^{22,23}$ or (more likely) through formaldehyde $\left(\mathrm{CH}_{2} \mathrm{O}\right)$-assisted ${ }^{24-26}$ routes - which can cyclize to form aromatic species. ${ }^{27-29}$ Aromatics can further co-catalyze the formation of alkenes in the aromatics cycle. ${ }^{1,16,30-32}$ Alternatively, aromatic species can react with dienes to form site-blocking polyaromatic spcies, ${ }^{11,33-36}$ which ultimately deactivate the catalyst. ${ }^{12}$ Therefore, $\mathrm{CH}_{2} \mathrm{O}$ and dienes play an important role in the formation of aromatic co-catalysts and deactivating polyaromatic molecules. ${ }^{13}$

High $\mathrm{H}_{2}$ pressures significantly improve catalyst lifetime in common MTO zeolites such as H-SAPO-34, HSSZ-13 (both the CHA framework) and H-ZSM-5 (MFI framework). ${ }^{37,38}$ Co-feeding $\mathrm{H}_{2}$ at high partial pressures (4-30 bar $\mathrm{H}_{2}, 0.13$ bar $\mathrm{CH}_{3} \mathrm{OH}, 673 \mathrm{~K}$ ) improved catalyst lifetime, as measured by turnover number, by a factor of 3-70 in H-SAPO-34. Similarly, $\mathrm{H}_{2}$ co-feeds at pressures of 0.4 bar in H-SSZ-13 and 16 bar in H-ZSM-5, HSSZ-39 (AEI framework), H-FER, and H-BEA improved catalyst lifetime by factors of 3-15 by measured turnovers. ${ }^{39}$ These extensions in catalyst lifetime did not result in dramatic changes in selectivity; while the alkane:alkene ratios generally increase, the predominant $\mathrm{C}_{2}-\mathrm{C}_{3}$ products remain as alkenes. Observed increases in $\mathrm{C}_{2}-\mathrm{C}_{4}$ alkane ratios are dependent on zeolite topology. For instance, $\mathrm{C}_{2}-\mathrm{C}_{4}$ alkane selectivity increases equally in $\mathrm{H}-\mathrm{CHA}, \mathrm{H}-\mathrm{BEA}$, and H-FER $\left(16\right.$ bar $\left.\mathrm{H}_{2}\right)$; however, propane selectivity is higher than that of $\mathrm{C}_{2}$ and $\mathrm{C}_{4}$ alkanes in $\mathrm{H}-\mathrm{AEI}$, indicating that zeolite topology plays a role in hydrogenation selectivities. Increases in catalyst lifetime likely occur because $\mathrm{H}_{2}$ selectively hydrogenates reactive species that lead to deactivation (e.g., dienes and formaldehyde), thereby limiting the amount of polyaromatic species formed during MTO. Kinetic studies of alkene and diene hydrogenation in CHA, FER, BEA, and AEI (0.1-1 mbar hydrocarbon, 1-16 bar $\left.\mathrm{H}_{2}, 623 \mathrm{~K}\right)$ corroborate the selective hydrogenation of dienes over alkenes by demonstrating that rate constants of butadiene $\left(\mathrm{C}_{4} \mathrm{H}_{6}\right)$ hydrogenation are 7-300x larger than those for ethene $\left(\mathrm{C}_{2} \mathrm{H}_{4}\right)$ and propene $\left(\mathrm{C}_{3} \mathrm{H}_{6}\right)$ in all frameworks.

Catalyst lifetimes can be further improved by combining high-pressure co-feeds of $\mathrm{H}_{2}$ and $\mathrm{H}_{2} \mathrm{O}$, which prolong the lifetime (as measured by methanol conversion dropping below 80\%) of H-SAPO-34 from 75 hours with cofed $\mathrm{H}_{2}$ (4.2 bar $\mathrm{CH}_{3} \mathrm{OH}, 35.7$ bar $\mathrm{H}_{2}, 723 \mathrm{~K}$ ) to 118 hours with cofed $\mathrm{H}_{2}$ and $\mathrm{H}_{2} \mathrm{O}$ (4.2 bar $\mathrm{CH}_{3} \mathrm{OH}, 22.8$ bar $\mathrm{H}_{2}, 12.8$ bar $\left.\mathrm{H}_{2} \mathrm{O}, 723 \mathrm{~K}\right) .{ }^{38} \mathrm{H}_{2} \mathrm{O}$ can assist in mitigating deactivation by increasing the surface coverage of protons (necessary for hydrogenation) by hydrating surface alkyl species (such as $\mathrm{CH}_{3}-\mathrm{Z}$ ) or by facilitating the protonation of dienes or formaldehyde by directly participating in hydrogenation steps.

There are two proposed mechanisms of Brønsted-acid catalyzed double-bond hydrogenation ${ }^{40,41}$ (Scheme 1): a concerted mechanism in which protonation of the double bond and cleavage of the $\mathrm{H}-\mathrm{H}$ bond occur simultaneously:

$$
\mathrm{C}_{x} \mathrm{H}_{2 x}+\mathrm{H}_{2}+\mathrm{Z}-\mathrm{H} \rightarrow \mathrm{C}_{x} \mathrm{H}_{2 x+2}+\mathrm{Z}-\mathrm{H}
$$

and a sequential mechanism in which a surface-bound alkyl species is first formed:

followed by subsequent hydridation by $\mathrm{H}_{2}{ }^{41,42}$

$$
\mathrm{C}_{x} \mathrm{H}_{2 x}+\mathrm{Z}-\mathrm{H} \rightarrow \mathrm{Z}-\mathrm{C}_{x} \mathrm{H}_{2 x+1}
$$

$$
\mathrm{Z}-\mathrm{C}_{x} \mathrm{H}_{2 x+1}+\mathrm{H}_{2} \rightarrow \mathrm{C}_{x} \mathrm{H}_{2 x+2}+\mathrm{Z}-\mathrm{H}
$$


These reactions, in the case of alkenes, are the microscopic reverse of dehydrogenation reactions which are a portion of acid-catalyzed alkane cracking (which causes a mixture of dehydrogenation and $\mathrm{C}-\mathrm{C}$ bond cleavage). ${ }^{1-}$ ${ }^{4}$ Previous reports investigating rates of $\mathrm{C}_{3}-\mathrm{C}_{6}$ cracking and dehydrogenation over H-ZSM-5 and H-YM zeolites has demonstrated that apparent energies of activation and rates of hydrogenation are directly proportional the carbon-chain length. ${ }^{43}$ These mechanisms involve the heterolytic splitting of $\mathrm{H}_{2}$ to transfer a hydride to an organic cation and a proton back to the catalyst surface; thus, isotopic tracer experiments are incapable of distinguishing these mechanisms. Moreover, both mechanisms may have similar kinetic isotope effects, if $\mathrm{H}_{2}$ splitting is the kinetically relevant transition state in both mechanisms. Previous density functional theory (DFT) calculations on $3 \mathrm{~T}$ cluster models examining hydrogenation of $\mathrm{C}_{2} \mathrm{H}_{4}$ and $\mathrm{CH}_{2} \mathrm{O}$ suggest that in the sequential mechanism, barriers of $\mathrm{Z}-\mathrm{C}_{2} \mathrm{H}_{5}$ formation (Eq. 2) are facile compared to its hydridation-indicating that the second step (heterolytic $\mathrm{H}_{2}$ cleavage, Eq. 3) is kinetically relevant in the sequential mechanism. ${ }^{42}$ Overall barriers (relative to the $\mathrm{Z}-\mathrm{H}$ state) of concerted and sequential hydrogenation are less than $10 \mathrm{~kJ} \mathrm{~mol}^{-1}$ different for $\mathrm{C}_{2} \mathrm{H}_{4},{ }^{42}$ indicating that the two mechanisms are likely competitive. Additionally, overall potential energy barriers of $\mathrm{CH}_{2} \mathrm{O}$ hydrogenation are facile $\left(60 \mathrm{~kJ} \mathrm{~mol}^{-1}\right)$ and are over $100 \mathrm{~kJ} \mathrm{~mol}^{-1}$ lower than those of ethene. Hydrogenation of $\mathrm{CH}_{2} \mathrm{O},{ }^{42}$ a diene precursor, ${ }^{8,26,44}$ may contribute to the experimentally observed increases in catalyst lifetime.

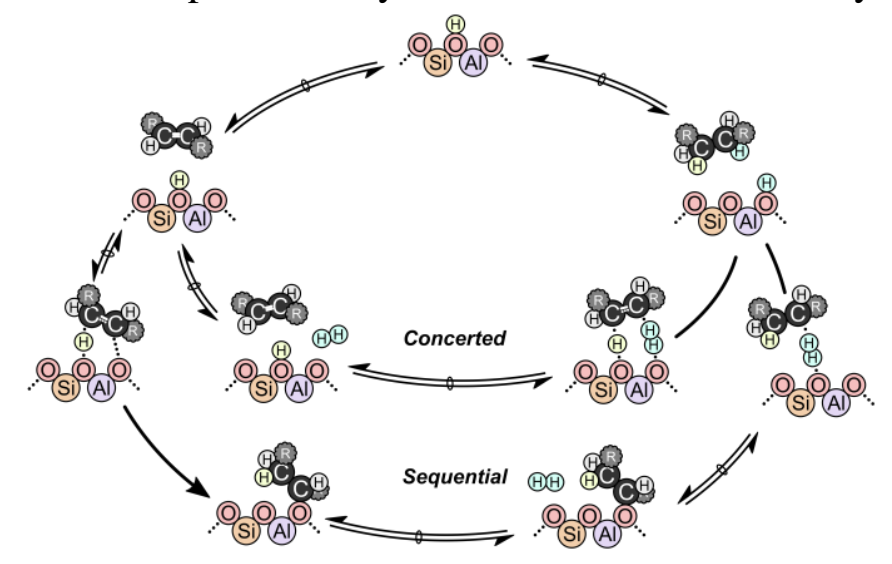

Scheme 1. Brønsted-acid catalyzed double-bond hydrogenation can occur via a concerted single-step pathway or via a two-step sequential pathway, both of which effectively exchange a surface proton with a proton atom derived from $\mathrm{H}_{2}$, indicating that these pathways cannot be distinguished by isotopic tracer studies.

The increases in catalyst lifetime observed by the previously discussed kinetic studies ${ }^{37-39}$ have demonstrated that hydrogenation reactions play an important role in increasing catalyst lifetime in zeolites of varying topologies. No theoretical study, however, has investigated and compared hydrogenation mechanisms across multiple alkenes, dienes, aldehydes, and arenes. Such theoretical analysis can provide insight inaccessible by experiment, such as contrasting mechanisms and assessing primary products, to improve understanding of how $\mathrm{H}_{2}$ improves lifetimes and alters the hydrocarbon pool or product selectivity in MTO reactions. Here, we use density functional theory (DFT) to examine concerted and sequential (Scheme 1) hydrogenation schemes of $\mathrm{C}_{2}-\mathrm{C}_{4}$ alkenes, $\mathrm{C}_{4}$ and $\mathrm{C}_{6}$ dienes, $\mathrm{CH}_{2} \mathrm{O}$, and benzene. We carry out these reactions in two common MTO zeolite frameworks: MFI and CHA, with the latter being modeled as an aluminosilicate H-SSZ-13 as well as a phosphoaluminosilicate HSAPO-34. We show hydrogenation of dienes and $\mathrm{CH}_{2} \mathrm{O}$ are kinetically favored over alkene and benzene hydrogenation in all three catalysts, suggesting that decreases in deactivation can be attributed to elimination of dienes (as $\mathrm{CH}_{2} \mathrm{O}$ is a diene precursor). Furthermore, these results indicate that diene hydrogenation preferentially occurs through protonation and hydridation of $\alpha, \delta(1,4) \mathrm{C}$-atoms to form 2-butene from butadiene and 3-hexene from 2,4-hexadiene. This $\alpha, \delta$ reaction mechanism is novel and more facile than other reactions that similarly proceed through an allylic carbocation, such as $\alpha, \beta$ hydrogenation of butadiene, indicating that the kinetic benefit 
of diene hydrogenation is not solely attributable to carbocation stability. Free energy barriers in aluminosilicate materials (H-ZSM-5 (MFI) and H-SSZ-13 (CHA)) are consistently lower than barriers in the phosphoaluminosilicate material examined (H-SAPO-34) - indicating that stronger acid frameworks facilitate hydrogenation better than those of weaker acids. Despite differences in overall barriers, trends in hydrogenation barriers tend to remain consistent across all three catalysts tested and barriers of butadiene and $\mathrm{CH}_{2} \mathrm{O}$ are consistently lower than those of alkenes and aromatics - indicating that the mechanism of hydrogenation does not significantly change based on catalyst selection.

\section{Methods}

\subsection{Computational Methods}

Periodic, dispersion-corrected density functional theory (DFT) calculations were carried out using the Vienna ab initio simulation package (VASP) $)^{45-48}$ as implemented in the Computational Catalysis Interface (CCI) ${ }^{49}$ Planewaves were constructed using the projector augmented-wave (PAW) potentials with an energy cutoff of 400 $\mathrm{eV}$. The Perdew-Burke-Ernzerhof (PBE) form of the generalized gradient approximation (GGA) was used to determine exchange and correlation energies. ${ }^{50-52}$ The DFT-D3 method with Becke and Johnson damping accounted for dispersive interactions. ${ }^{53-55}$ The Brillouin zone was sampled at the $\Gamma$-point for all calculations. ${ }^{56}$ Previous work benchmarking accuracy of different DFT functionals has demonstrated that PBE-D3 underestimates activation barriers for methanol dehydrogenation and other reactions (relative to CCSD methods) and that these errors can be limited by employing higher level calculations such as M02 which decreases errors to $\sim 7 \mathrm{~kJ} \mathrm{~mol}^{-1} \cdot{ }^{57}$ However, this work focuses on comparing trends in energy barriers, rather than comparing DFTobtained energy barriers directly to experimental results or higher-level methods. To confirm that these trends are not dependent on the choice of functional, five transition states were also examined using the BEEF-vdw functional (Figure S7) and the trends remain the same regardless of functional choice - thus, the remainder of this paper will discuss our results with PBE-D3.

The MFI structure obtained from the experimental results of van Koningsveld et al. ${ }^{58}$ is used in all MFIcalculations because restructuring artifacts are minimized in this zeolite form (Fig. S1). ${ }^{59}$ The lattice parameters $(\mathrm{a}=20.090 \AA, \mathrm{b}=19.738 \AA, \mathrm{c}=13.142 \AA$ ) and orthorhombic shape were fixed in all calculations. All calculations in MFI were performed with a single Brønsted acid site (Si:Al of 95) at the T11 tetrahedral site (T-site), which has been predicted to have lower $\mathrm{Z}-\mathrm{CH}_{3}$ formation barriers than other $\mathrm{T}$-sites residing in the channel intersection (T3, T10, and T12). ${ }^{6}$ There are four O-sites surrounding T11: O14, O16, O24, and O25. Previous work has demonstrated that $\mathrm{O} 24$ is inaccessible to species larger than $\mathrm{CH}_{3}-\mathrm{Z}$, because of confinement by the surrounding framework; ${ }^{61}$ therefore, reactions were investigated at $\mathrm{O} 14, \mathrm{O} 16$, and $\mathrm{O} 25$, and their respective combinations for reactions involving two $\mathrm{O}$ atoms. The $\mathrm{CHA}$ structure (Fig. S2) was obtained from the International Zeolite Association (IZA) database - no significant restructuring artifacts are observed upon annealing or optimization of the CHA structure. ${ }^{59}$ The lattice parameters $\left(\mathrm{a}=\mathrm{b}=13.675 \AA, \mathrm{c}=16.675 \AA\right.$ and $\left.\alpha=\beta=90^{\circ}, \gamma=120^{\circ}\right)$ were fixed in all calculations. All reactions in CHA were performed with a single Brønsted acid site at the single cryptographically unique T-site of CHA corresponding to a Si:Al ratio of 35 . All four O-sites surrounding that Tsite were considered for all reactions (and in all combinations for sites which directly interact with a pair of $\mathrm{O}$ atoms). The H-SAPO-34 (Fig. S3) lattice parameters ( $a=13.8704, b=13.8733, c=14.9725, \alpha=90.02, \beta=89.99$, $\gamma=119.98$ ) and atomic positions were optimized using an $800 \mathrm{eV}$ energy cutoff and so that energies between iterations differed by $<1 \times 10^{-6} \mathrm{eV}$. H-SAPO-34 was modeled with a single $\mathrm{Si}$ atom, corresponding to a $\mathrm{Al}+\mathrm{P}: \mathrm{Si}$ ratio of 35 (and thus having the same site density as the H-SSZ-13 model).

Reactants, products, and adsorbed intermediates were optimized until the maximum force on any atom was < $0.05 \mathrm{eV}^{-1}$ in a two-step convergence procedure as implemented in CCI. ${ }^{49}$ In the first step, wavefunctions were 
converged to within $10^{-4} \mathrm{eV}$ and forces were computed using a fast Fourier transform (FFT) grid with a cutoff $1.5 \times$ the planewave cutoff. In the second step, accuracy was improved by converging wavefunctions to within $10^{-6} \mathrm{eV}$ and using an FFT grid $2 \times$ the planewave cutoff. No atoms were constrained in any DFT optimization, pathway, or transition state calculations. Minimum energy pathways were estimated using the nudged elastic band (NEB) method $^{62}$ using 12-16 images and wavefunctions converged to $10^{-4} \mathrm{eV}$ with an FFT grid $1.5 \times$ the size of the plane-wave cutoff. The maximum force on each atom in all images were converged to $<0.5 \mathrm{eV} \AA^{-1}$ for $\mathrm{NEB}$ calculations. This estimate of the minimum energy pathway was used to generate initial transition state structures and reaction modes for the Dimer method, ${ }^{63}$ which optimizes a pair of structures to determine the local curvature of the potential energy surface until ultimately converging on a saddle point. Dimer calculations were done in an analogous two-step optimization procedure using the same convergence criteria as reactant, product, and intermediate optimizations. All DFT-optimized reactant, product, and transition states were modeled at all relevant $\mathrm{O}$-sites and $\mathrm{O}$-site pairs (if the species interacted with a pair of $\mathrm{O}$ atoms) associated with T11 of MFI and T1 of CHA. Furthermore, all structures were systematically reoriented (Section 2.2), ${ }^{61}$ to increase the likelihood that global minima and optimum transition state structures were obtained via static (non-dynamic) DFT calculations. Converged NEB and Dimers in the H-SSZ-13 framework (aluminosilicate CHA framework, Section 3.3) were transferred to the H-SAPO-34 framework (phosphoaluminosilicate CHA framework) using CCI tools, as described in our recent manuscript. ${ }^{49}$

Frequencies were calculated for all reactant, product, and transition states using a fixed displacement method where the adsorbates (e.g., $\mathrm{CH}_{3} \mathrm{OH}$ and benzene) and $\mathrm{AlO}_{4}$ of the acid site are displaced while all other framework atoms are fixed. Low-frequency modes $\left(<60 \mathrm{~cm}^{-1}\right)$ were replaced with $60 \mathrm{~cm}^{-1}$, similar to previous work, ${ }^{64}$ because low frequencies are inaccurate and contribute significantly to vibrational entropy terms. These frequency calculations are used to determine zero-point vibrational energies and vibrational enthalpies and entropies which can be combined with ideal gas treatments of rotational and translational modes (for bulk gas species) to determine temperature-corrected (353-673 K) enthalpies and free energies using equations given in Section S3 of the supporting information (SI).

\subsection{Reorientation of Reactant, Product, and Transition State Species}

All reactant, product, and transition state structures were modeled on the three accessible O-sites of T11 in MFI (O14, O16, and O24) and at all four unique O-sites in CHA (O1, O2, O3, and O4). Each reactant, product, and transition state structure was systematically reoriented as implemented in $\mathrm{CCI}^{49}$ in an attempt to identify the global minimum, rather than local minima. These reorientations can find configurations of guest species with

energies as much as $50 \mathrm{~kJ} \mathrm{~mol}^{-1}$, as discussed in previous work, ${ }^{65}$ and are often neglected in studies which improve accuracy with higher-level methods.

Reorientation schemes are based upon how an adsorbate interacts with the zeolite. States that interact nonspecifically with the Brønsted acid site (e.g., adsorbed alkenes, dienes, and protonated states) are reoriented in space about the axes defined by the a-, b-, and c-vectors of the unit cell around their centers of mass (Fig. 1a). The orientation of each state was varied in $30^{\circ}$ increments from $30-330^{\circ}$ around each of these rotational axes individually and subsequently optimized with the parameters discussed in Section 2.1 to identify the lowest energy orientation. 


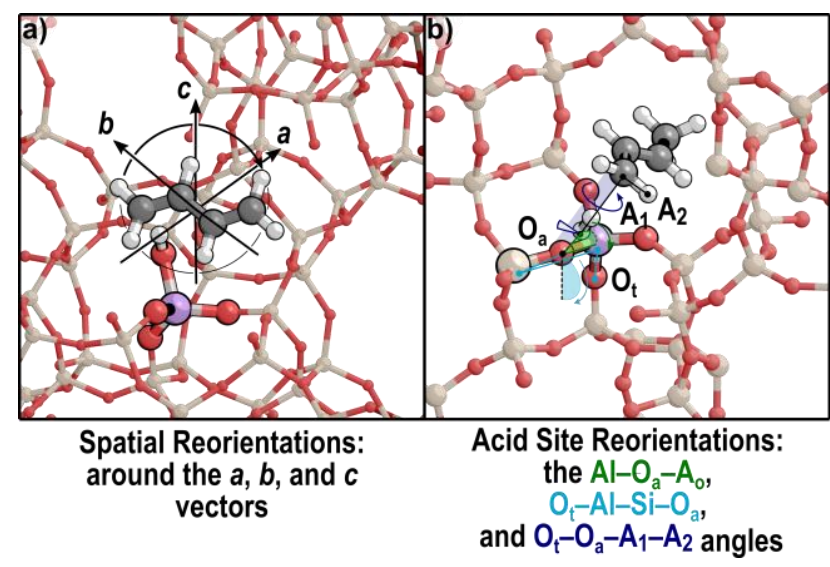

Figure 1. a) Spatial reorientations of butadiene about the a-, b-, and c-axes of the unit cell and b) acid site reorientations of the hydrogenation of $\mathrm{C}_{4} \mathrm{H}_{6}$ (transition state) about the $\mathrm{Al}-\mathrm{O}_{\mathrm{a}}-\mathrm{A}_{1}$ angle (green), $\mathrm{O}_{t}-\mathrm{Al}-\mathrm{Si}-\mathrm{O}_{\mathrm{a}}$ angle (cyan), and $\mathrm{O}_{\mathrm{t}}-\mathrm{O}_{\mathrm{a}}-\mathrm{A}_{1}-\mathrm{A}_{2}$ (blue).

States that interact strongly with the framework — via covalent, incipient, or hydrogen bonds — are reoriented about the acid site. Three types of acid site reorientations are used here: $\mathrm{O}_{t}-\mathrm{Al}-\mathrm{Si}-\mathrm{O}_{\mathrm{a}}(\mathrm{Fig}$. $1 \mathrm{~b}), \mathrm{Al}-\mathrm{O}_{\mathrm{a}}-\mathrm{A}_{1}$, and $\mathrm{O}_{t}-\mathrm{O}_{a}-\mathrm{A}_{1}-\mathrm{A}_{2}$, which have been described in previous literature. ${ }^{61}$ Reorientations about the $\mathrm{O}_{t}-\mathrm{Al}-\mathrm{Si}-\mathrm{O}_{\mathrm{a}}$ dihedral angle sweep the adsorbate around the Brønsted acid site (Fig. 1b). The orientations of these states were varied in $30^{\circ}$ increments from $30-330^{\circ}$ and all converged states were subsequently optimized. Altering the $\mathrm{Al}-\mathrm{O}_{\mathrm{a}}-\mathrm{A}_{1}$ angle moves the adsorbed state parallel to the acid site through the zeolite void (Fig. 1b). Each state was reoriented in $15^{\circ}$ increments between $-30^{\circ}$ and $30^{\circ}$, and the four resulting states were reoptimized using the parameters discussed in Section 2.1. Finally, $\mathrm{O}_{\mathrm{t}}-\mathrm{O}_{\mathrm{a}}-\mathrm{A}_{1}-\mathrm{A}_{2}$ reorientations result in guest species spun about their interaction with the $\mathrm{O}$ atom with which they interact on the acid site or its conjugate base (Fig. 1b). These $\mathrm{O}_{\mathrm{t}}-\mathrm{O}_{\mathrm{a}}-\mathrm{A}_{1}-\mathrm{A}_{2}$ reorientations were done in $30^{\circ}$ increments from $30-330^{\circ}$. Reactant and product states that are covalently bound to the zeolite surface (e.g., $\mathrm{C}_{2} \mathrm{H}_{5}-\mathrm{Z}$ ) are reoriented with $\mathrm{O}_{t}-\mathrm{Al}-\mathrm{Si}-\mathrm{O}_{\mathrm{a}}$ and $\mathrm{O}_{t}-\mathrm{Al}-\mathrm{Si}-\mathrm{O}_{\mathrm{a}}$ reorientations (covalently bound states are ineligible for $\mathrm{Al}-\mathrm{O}_{\mathrm{a}}-\mathrm{A}_{1}$ reorientations) to probe the potential energy surface. States that are not covalently bound but strongly interact with the surface through either hydrogen bonding $\left(\right.$ e.g., $\left.\mathrm{CH}_{2} \mathrm{O}\right)$ or nascent bonds (e.g., sequential hydrogenation) are rotated through all acid site reorientation schemes.

The alkoxide-forming transition state (Eq. 2) and the concerted hydrogenation transition state (Eq. 1) strongly interact with two O-sites simultaneously. Therefore, reorientations of these states would significantly change the transition state strucutre and, as such, these states were not systematically reoriented. However, each transition state was examined between all possible O-site combinations among the 3 accessible O-sites in MFI and 4 accessible O-sites in CHA, resulting in 6 optimized transition state structures for these transition states in MFI and 10 optimized transition states in $\mathrm{CHA}$.

\section{Results and Discussion}

\subsection{Hydrogenation Thermodynamics}

Hydrogenation reactions were investigated for all possible hydrogenation products of ethene, propene, 1butene, 2-butene, butadiene, 2,4-hexadiene, formaldehyde, and benzene (Fig. 2). Gas phase reaction energies (Fig. 2) indicate that there is no significant thermodynamic preference to hydrogenate species involved in polyaromatic formation (aromatics, dienes, and formaldehyde) compared to alkenes, and that $\mathrm{C}=\mathrm{C}$ bond stability increases with $\mathrm{C}$-atom substitution. This indicates that the tendency for dienes to be hydrogenated over alkenes-as shown experimentally ${ }^{39}$ - arises from a kinetic preference, likely because of the resonance-stabilized allylic carbocations which mediate some diene hydrogenation pathways. A preference for formaldehyde hydrogenation over alkene hydrogenation has not been directly observed, but has been predicted by DFT calculations contrasting 
formaldehyde and ethene hydrogenation and demonstrating that the former is stabilized by the formation of oxocarbenium ions. ${ }^{42}$ Despite the stability of the benzenium $\left(\mathrm{C}_{6} \mathrm{H}_{7}{ }^{+}\right)$cation, the disruption of the aromaticity results in a large reaction free energy $\left(+94 \mathrm{~kJ} \mathrm{~mol}^{-1}\right)$ and the instability of the cyclohexadiene product is likely to limit benzene hydrogenation rates. Direct analysis of both hydrogenation mechanisms (sequential and concerted) and altering which carbon is protonated and which is hydridated during these reactions will give additional insights.

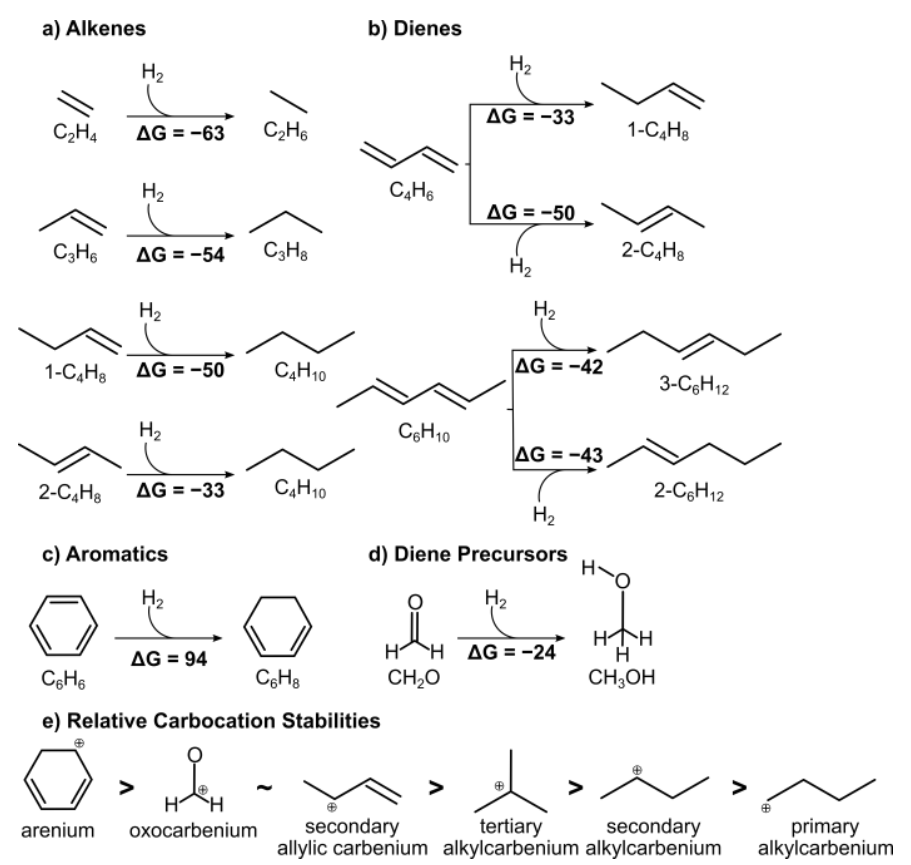

Figure 2. Gas phase reaction energies of a) alkene hydrogenation, b) diene hydrogenation, c) aromatic hydrogenation, and d) formaldehyde hydrogenation.

\subsection{Hydrogenation in H-MFI}

Two hydrogenation schemes were considered in this work: a concerted mechanism in which protonation and hydridation occur simultaneously and a sequential mechanism in which the alkene is protonated and forms a zeolite-bound intermediate followed by hydridation by $\mathrm{H}_{2}$. These mechanisms were investigated for all reactants, except benzene and hexadiene where only the concerted mechanism was considered because of the difficulty of forming bound benzenium alkoxy species.

Sequential hydrogenation generally involves the formation of a surface-bound species $\left(\mathrm{Z}-\mathrm{C}_{2} \mathrm{H}_{5}\right.$ for ethene) followed by subsequent hydridation by $\mathrm{H}_{2}$. Formation of $\mathrm{Z}-\mathrm{C}_{2} \mathrm{H}_{5}$ involves simultaneous protonation of the $\alpha$ carbon and $\mathrm{C}-\mathrm{O}$ bond formation with the $\beta$ carbon (Fig. 3). The transition state with the lowest energy among all six distinct $\mathrm{O}$-site pair possibilities is shown in Fig. 3b, and the effective free energy barrier to form this transition state (relative to gas-phase species and a bare proton) is $118 \mathrm{~kJ} \mathrm{~mol}^{-1}$ with an intrinsic barrier of $92 \mathrm{~kJ} \mathrm{~mol}^{-1}$ (Fig. 4). The second step of the sequential mechanism involves detachment and rotation of $\mathrm{C}_{2} \mathrm{H}_{5}{ }^{+}$so that heterolytic $\mathrm{H}_{2}$ dissociation can occur (Fig. 3c) to transfer a hydride to the carbocation and a proton to the zeolite surface and occurs with an effective free energy barrier of $220 \mathrm{~kJ} \mathrm{~mol}^{-1}$. The free energy barriers of the two sequential hydrogenation steps (118 and $220 \mathrm{~kJ} \mathrm{~mol}^{-1}$ ) cannot be directly compared to evaluate their relative rates because the second step requires $\mathrm{H}_{2}$ adsorption as such the pressure dependences in their respective rate equations differ:

$$
\begin{gathered}
\frac{r_{S 1}}{[L]}=K_{C_{2} H_{4}} k_{S 1}\left(C_{2} H_{4}\right)[*]^{-1} \\
\frac{r_{S 2}}{[L]}=K_{C_{2} H_{4}} K_{C_{2} H_{4} \cdots H_{2}} K_{S 1} k_{S 2}\left(C_{2} H_{4}\right)\left(H_{2}\right)[*]^{-1}
\end{gathered}
$$


with rate and equilibrium constants defined in Section S4 of the SI and [*] indicating a bare proton on the zeolite surface. Bare protons $\left(^{*}\right)$ will not be abundant at MTO conditions, however, surface methoxies or other species will equally inhibit the rates of both steps (and equally inhibit all reactions studied in this work), as such, the presence of absence of site-blocking intermediates can be neglected in the analysis of relative hydrogenation rates and the relative rates of the steps within the sequential and concerted hydrogenation mechanisms. To determine which step in this sequence is the rate determining step, the sequential mechanism is analyzed using maximum rate analysis (described in Section S4 of the SI) to determine the kinetically relevant step by comparing the maximum rates of alkoxide formation and $\mathrm{H}_{2}$ splitting. Protonated benzene and hexadiene cations are too stable and sterically hindered to form bound alkoxides, so these species were only investigated by the concerted hydrogenation mechanism. For formaldehyde, butadiene, and all alkenes studied here, alkoxide hydridation (Eq. 3) had maximum rates over 400× lower than alkoxide formation (Eq. 2) at all relevant conditions (553-723 K, 120 bar $\mathrm{H}_{2}, 0.01-0.15$ bar reactant, Fig. S4 of the SI); indicating that alkoxide formation from unsaturated compounds will be quasi-equilibrated within the timescale of hydrogenation reactions and therefore, subsequent discussion will focus on alkoxide hydridation as it is the kinetically relevant step of the sequential mechanism in all zeolite frameworks investigated (Figs. S4-S6).

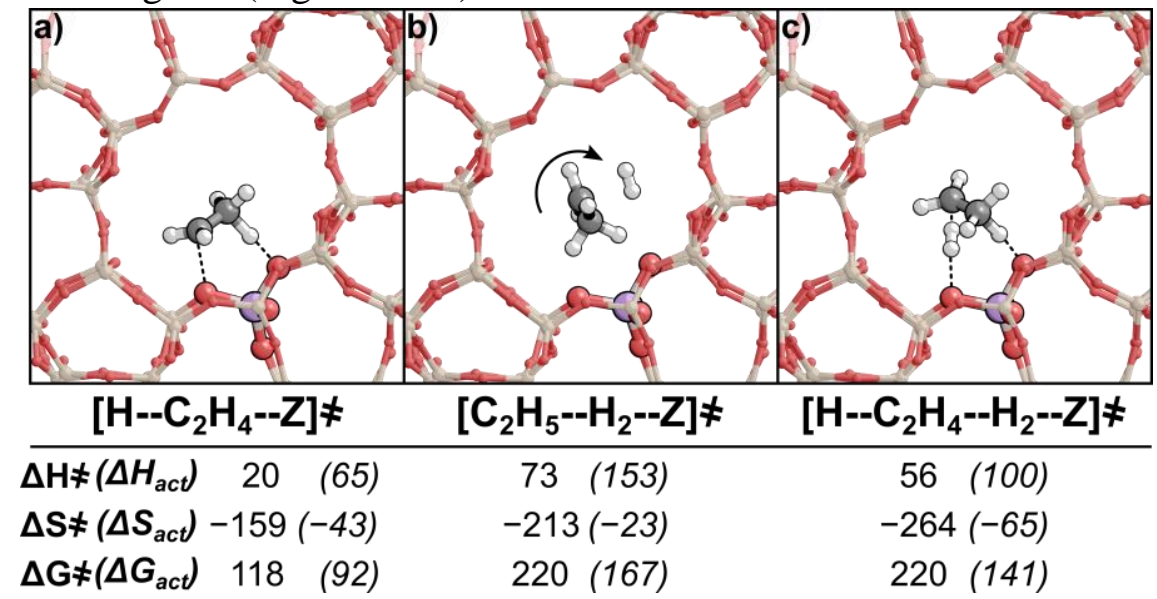

Figure 3. Transition state structures of a) $\mathrm{Z}-\mathrm{C}_{2} \mathrm{H}_{5}$ formation, b) alkoxide hydridation, and c) concerted hydrogenation in MFI. Enthalpy $\left(\mathrm{H}, \mathrm{kJ} \mathrm{mol}^{-1}\right)$, entropy $\left(\mathrm{S}, \mathrm{J} \mathrm{mol}^{-1} \mathrm{~K}^{-1}\right)$ and free energy $\left(\mathrm{G}, \mathrm{kJ} \mathrm{mol}^{-1}\right)$ barriers are reported at $623 \mathrm{~K}$ and 1 bar. Effective barriers (referenced to gas-phase species and a bare proton, $\Delta \mathrm{G} \neq$ ) and intrinsic barriers (in parentheses, $\Delta \mathrm{G}_{\text {act }}$ ) are both listed. Transition states for $\mathrm{C}_{3}-\mathrm{C}_{6}$ species are shown in Section S7 of the Supplementary Information.

The most facile concerted ethene hydrogenation transition state involves simultaneous protonation from $\mathrm{O} 14$ and heterolytic $\mathrm{H}_{2}$ splitting to re-form a proton at $\mathrm{O} 16$ with the organic compound residing in the straight channel (Fig. 3c), rather than the channel intersection. Exploring the effects of transition state confinement is crucial to understanding the effects of topology on zeolite catalyzed reactions, as such each of the reactions in this work was investigated at all possible O-site combinations within MFI and systematically reoriented as described in Section 2.2. Generally, aliphatic compounds, such as $\mathrm{C}_{2} \mathrm{H}_{4}$, reside in the straight channel of MFI as it is appropriately sized for small transition states, where dispersive interactions between transition state and the framework are most favorable. This reaction occurs with an identical $\Delta G \ddagger\left(220 \mathrm{~kJ} \mathrm{~mol}^{-1}\right)$ to that of ethoxide hydridation (Fig. 3b), indicating that the concerted and sequential mechanisms compete at $623 \mathrm{~K}$, while having slightly different $\Delta H \neq\left(73\right.$ and $56 \mathrm{~kJ} \mathrm{~mol}^{-1}$ for alkoxide hydridation and concerted hydrogenation, respectively) indicate that other temperatures may lead to a single dominant mechanism. Concerted and sequential free energy barriers are similar for all species as the transition state for both structures primarily involve a carbocation (fully or partially formed) interacting with a cleaving $\mathrm{H}_{2}$ molecule which is also interacting with the zeolite framework. 
Moreover, their rate equations reflect identical pressure dependences and, thus, these data yield identical predicted rates for each pathway in ethene hydrogenation at $623 \mathrm{~K}$-making them indistinguishable by kinetic studies.

DFT-predicted kinetic isotope effects (KIE) for the concerted and sequential mechanisms are 2.4 and 2.6, respectively, for $1-\mathrm{C}_{4} \mathrm{D}_{8}-\mathrm{D}_{2}$ reactions over D-MFI. Furthermore, KIE values are 1.7 and 1.1 for $\mathrm{C}_{2} \mathrm{D}_{4}-\mathrm{H}_{2}$ reactions over D-MFI. These are the only meaningful D-involving reactions as $\mathrm{H} / \mathrm{D}$ on $\mathrm{C}_{2} \mathrm{H}_{4}$ and the zeolite surface will scramble in the quasi-equilibrated formation of alkoxides (or protonated complexes) from unsaturated compounds. These KIE values for 1-butene hydrogenation, furthermore, are not affected by the zeotype catalyst or by the reactant being considered, as shown in Table S1 of the SI. Ultimately, the predicted KIE values for the concerted and sequential mechanisms for completely or partially deuterated reactions are likely too close to one another to provide an effective experimental discrimination between these two reaction mechanisms.

Effective free energy barriers for ethene hydrogenation are at least $40 \mathrm{~kJ} \mathrm{~mol}^{-1}$ higher than all other alkene species (Fig. 4), because the short-lived primary carbenium ion $\left(\mathrm{C}_{2} \mathrm{H}_{5}{ }^{+}\right)$is unstable relative to the secondary carbenium ions that can be formed from larger alkenes. Kinetic studies in H-ZSM-5 (MFI) indicate that there are not significant changes in $\mathrm{C}_{2} \mathrm{H}_{4}$ selectivity $\left(16\right.$ bar $\mathrm{H}_{2}, 0.13$ bar $\mathrm{CH}_{3} \mathrm{OH}, 723 \mathrm{~K}$ ) or increase in $\mathrm{C}_{2} \mathrm{H}_{6}$ selectivity ${ }^{37}$ which is consistent with the DFT-derived free energy barriers that indicate ethene hydrogenation is relatively slow.

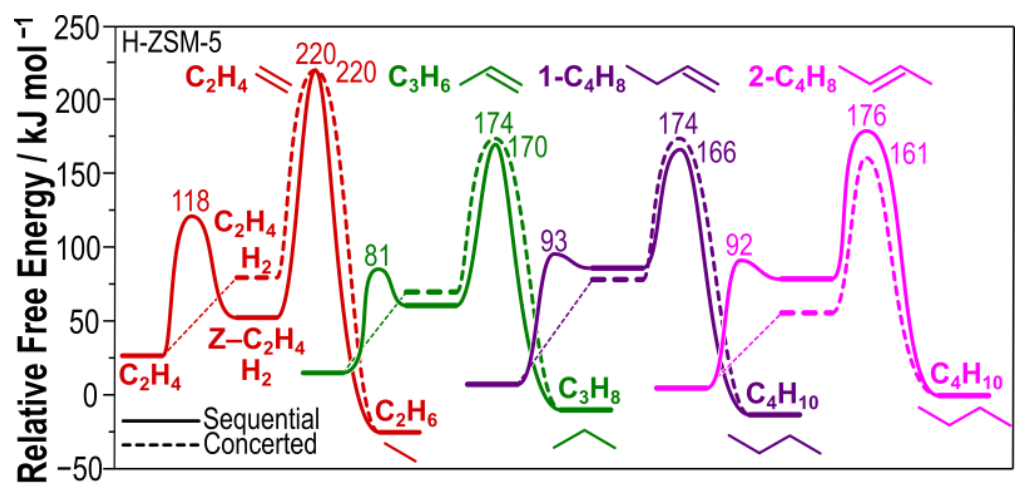

Figure 4. Reaction coordinate diagram of ethene (red), propene (green), 1-butene (purple), and 2-butene (pink) concerted (dashed) and sequential (solid) hydrogenation routes. Free energies $\left(\mathrm{kJ} \mathrm{mol}^{-1}\right)$ are reported at $623 \mathrm{~K}$ and 1 bar of each alkene and 1 bar $\mathrm{H}_{2}$. All enthalpy, entropy, and free energy barriers are reported in Table S3 and transition state structures are shown in Section S7.

There are two unique hydrogenation schemes for propene: formation of a primary carbocation by protonation the secondary $(\beta)$ carbon (Fig. 5b) or formation of a secondary carbocation by protonation of the primary $(\alpha)$ carbon (Fig. 5c). Secondary carbocations are significantly more stable than primary carbocations, leading to lower hydrogenation barriers (Fig. 5a) via those species. DFT calculations on 8T clusters of H-ZSM-5 demonstrate that barriers of dehydrogenation occurring on the $\beta$-carbon are $50-55 \mathrm{~kJ} \mathrm{~mol}^{-1}$ lower than dehydrogenation at the $\alpha$ carbon, ${ }^{66}$ further demonstrating the stability of secondary carbocations in these reactions. This trend is consistent across all species investigated (Fig. 5a), indicating that carbocation stability is a good predictor of hydrogenation barriers among similar reactants (such as alkenes). The $\Delta G \neq$ for propene hydrogenation via concerted and sequential hydrogenation (174 and $170 \mathrm{~kJ} \mathrm{~mol}^{-1}$ ) are similar to one another, indicating that both mechanisms compete in MFI, and are lower than those of ethene $\left(220 \mathrm{~kJ} \mathrm{~mol}^{-1}\right)$ as shown in Fig. 4 because propene hydrogenation occurs via secondary carbenium ions. This is corroborated by experimental results that indicate small increases in $\mathrm{C}_{3}$ alkane selectivity $\left(16\right.$ bar $\mathrm{H}_{2}, 0.13$ bar $\mathrm{CH}_{3} \mathrm{OH}, 723 \mathrm{~K}$ ) ${ }^{37}$ and that rate constants of ethene hydrogenation in H-SSZ-13 (CHA), H-SSZ-39 (AEI), H-FER, and H-BEA are 1.5-16× lower than rate constants of propene hydrogenation. ${ }^{39}$ 


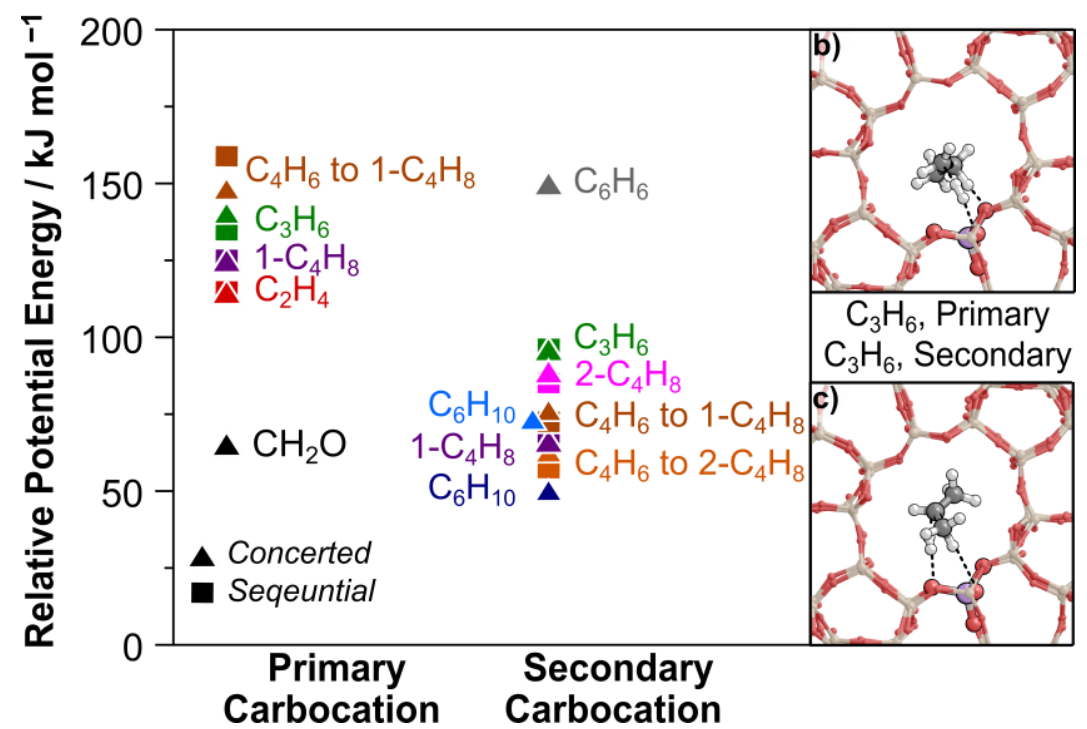

Figure 5. a) Intrinsic potential energy concerted (triangle) and sequential (square) hydrogenation energies, and b) primary and b) secondary hydrogenation schemes to form primary and secondary carbocations via concerted hydrogenation of $\mathrm{C}_{3} \mathrm{H}_{6}$.

Concerted hydrogenation of 1-butene, like propene, also occurs by protonation of the primary $\alpha-\mathrm{C}$ and hydridation of the secondary $\beta$-C (Fig. 6c). Routes via secondary carbenium ions have $\Delta G \neq$ that are $>60 \mathrm{~kJ} \mathrm{~mol}^{-1}$ lower than routes proceeding via primary carbenium ions (Fig. 5a). The effective free energy barriers for hydrogenating 1-butene and 2-butene are nearly identical 166 and $161 \mathrm{~kJ} \mathrm{~mol}^{-1}$ (Fig. 4) -indicating that hydrogenation is equally as likely to occur regardless of the n-butene isomer present in the hydrocarbon pool; while isobutene is the most thermodynamically stable butene isomer, here we focused on 1- and 2-butene as these are the primary products of butadiene hydrogenation. Butene hydrogenation barriers are significantly lower than those of ethene but within $9 \mathrm{~kJ} \mathrm{~mol}^{-1}$ of propene suggesting that alkylcarbeniums stability plays a larger role than carbon chain length in alkyl hydrogenation rates. As such, branched alkenes such as isobutene would most readily be hydrogenated, followed by $n$-alkenes $(n>2)$, and then ethene as carbenium stabilities trend $1^{\circ}<2^{\circ}<3^{\circ}$.

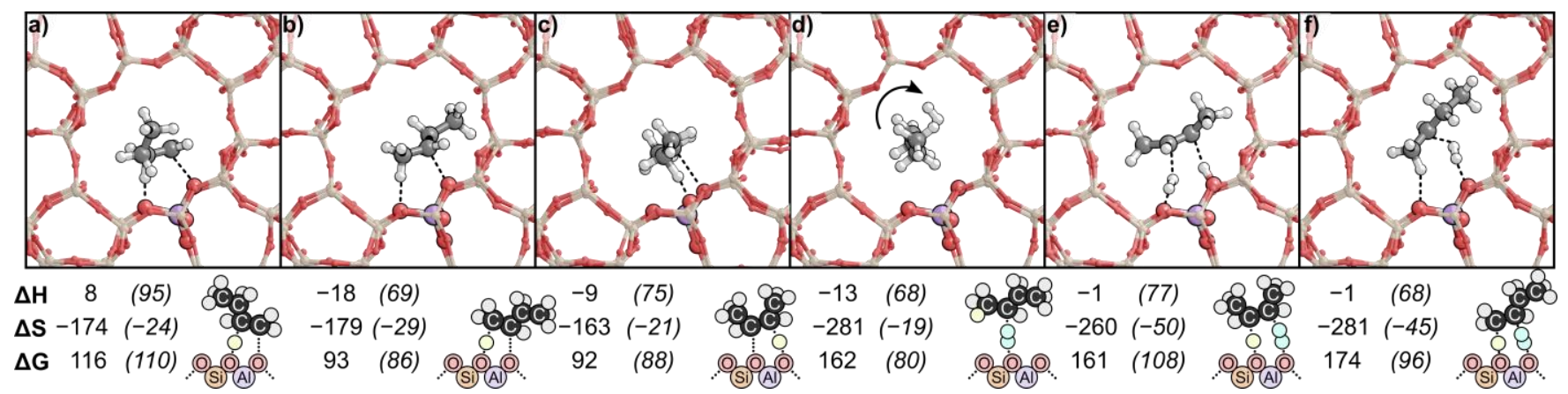

Figure 6. Most favorable transition state structures of hydridating a) $\alpha$-bound alkoxide from 1-butene, b) $\beta$-bound alkoxide from 1-butene, c) $\beta$-bound alkoxide from 2-butene, d) hydridation of the $\beta$-bound alkoxide and the concerted hydrogenation transition states for d) 1-butene, and e) 2-butene. Enthalpy $\left(\mathrm{H}, \mathrm{kJ} \mathrm{mol}^{-1}\right)$, entropy (S, J $\left.\mathrm{mol}^{-1} \mathrm{~K}^{-1}\right)$ and free energy $\left(\mathrm{G}, \mathrm{kJ} \mathrm{mol}^{-1}\right)$ barriers are reported at $623 \mathrm{~K}$ and 1 bar. Effective barriers (referenced to gas-phase species, $\Delta \mathrm{G}^{\neq}$) and intrinsic barriers (in parentheses, $\Delta \mathrm{G}_{\text {act }}$ ) are both listed. Yellow and blue shaded $\mathrm{H}$-atoms represent those from the zeolite and $\mathrm{H}_{2}$, respectively.

Dienes can react with aromatics to form large polyaromatic species that deactivate zeolite catalysts; therefore, elimination of butadiene species through hydrogenation is one possible mechanism through which $\mathrm{H}_{2}$ co-feeds 
elongate catalyst lifetime. Measured second order rate constants of butadiene hydrogenation in H-CHA (H-SSZ13), H-SSZ-39, H-FER, and H-BEA are 7-300× larger than rate constants of ethene and propene hydrogenation, suggesting that butadiene is selectively hydrogenated regardless of zeolite topology. ${ }^{39}$ This selective butadiene hydrogenation, however, is not because of a thermodynamic preference as reaction free energies for diene hydrogenation ( -33 to $-50 \mathrm{~kJ} \mathrm{~mol}^{-1}$ ) are similar to those of alkene hydrogenation ( -33 to $-63 \mathrm{~kJ} \mathrm{~mol}^{-1}$ ) (Fig. 2). Butadiene can be hydrogenated to form 1-butene (via $\alpha, \beta$ attack) and 2-butene (via $\alpha, \delta$ attack) leading to four unique alkoxide hydridation reactions (Eq. 3, Figs. 8a-d) and two unique concerted hydrogenation routes (Eq. 1, Fig. 8 e, f). The alkoxide hydridation transition states depicted in Figs. 8a-c involve formation of a carbenium (Fig. 8a is non-allylic while Figs. 8b and c are allylic) followed by rotation to reach the orientation in which hydridation occurs, as such the transition state for these species involves both rotation and $\mathrm{H}_{2}$ stretching. The transition state shown in Fig. 8d represents alkoxide hydridation; however, unlike Figs. 8a-c, this route does not require rotation of $\mathrm{C}_{4} \mathrm{H}_{7}{ }^{+}$because the $\delta$-carbon is being hydridated (rather than the surface-bound carbon), and occurs with the lowest sequential barrier (by $>7 \mathrm{~kJ} \mathrm{~mol}^{-1}$ ) of $144 \mathrm{~kJ} \mathrm{~mol}^{-1}$. Alkoxide hydridation transition state barriers (Figs. 8a-8d) tend to reflect the stability of carbenium formed; barriers among transition states with secondary allylic carbeniums (Figs. 8b-d) are between $144-154 \mathrm{~kJ} \mathrm{~mol}^{-1}$ and are $70 \mathrm{~kJ} \mathrm{~mol}^{-1}$ lower in $\Delta \mathrm{G} \neq$ than the reaction via a non-allylic primary carbenium cation (Fig. 8a). Furthermore, the formation of secondary allylic carbocations results in transition states $\sim 10 \mathrm{~kJ} \mathrm{~mol}^{-1}$ lower than secondary alkylcarbenium transition states (161$166 \mathrm{~kJ} \mathrm{~mol}^{-1}$, Fig. 4) for butene hydrogenation. The concerted hydrogenation transition state is later than those observed for $\mathrm{C}_{2}-\mathrm{C}_{4}$ alkenes and primarily involves hydridation, at either the $\beta$ (Fig. 8f) or $\delta$ (Fig. 8e) positions, of an $\alpha$ protonated complex, rather than simultaneous protonation and hydridation. Concerted protonation and hydridation at the $\alpha, \delta$ position to form 2-butene results in $\Delta \mathrm{G} \neq 28 \mathrm{~kJ} \mathrm{~mol}^{-1}$ lower than at the $\alpha, \beta$ position to form 1-butene, despite both reactions forming a secondary, allylic carbocation. Butadiene hydrogenation occurs with barriers up to $20 \mathrm{~kJ} \mathrm{~mol}^{-1}$ lower than those of butene; however, this preference is not fully explained by increased carbocation stabilities as butadiene shows a unique preference of $\alpha, \delta$-hydrogenation schemes. Furthermore, barriers of $\alpha, \beta$-hydrogenation of butadiene $\left(\Delta \mathrm{G} \neq\right.$ of $154-162 \mathrm{~kJ} \mathrm{~mol}^{-1}$, Fig. 7) are essentially identical to propene and butene hydrogenation barriers ( $\Delta \mathrm{G} \neq$ of $161-170 \mathrm{~kJ}$ mol ${ }^{-1}$, Fig. 4), while $\alpha, \delta$-hydrogenation of butadiene occurs with a barriers of 135-144 $\mathrm{kJ} \mathrm{mol}^{-1}$. The preference to form 2-butene from butadiene cannot be experimentally verified as double bond and skeletal isomerization are facile resulting in an equilibrated mixture of isobutene, 1-butene, and 2-butene at MTO and hydrogenation conditions. This inability of experiments to determine the primary butadiene hydrogenation product further motivates our theoretical studies. Overall, formation of allylic carbocations results in energy barriers $>10 \mathrm{~kJ} \mathrm{~mol}^{-1}$ lower than those of alkylcarbeniums, further demonstrating that these barriers are governed by carbocation stabilities and the availability of $\alpha, \delta$ hydrogenation schemes which we hypothesize reduce steric hindrances associated with hydridation.

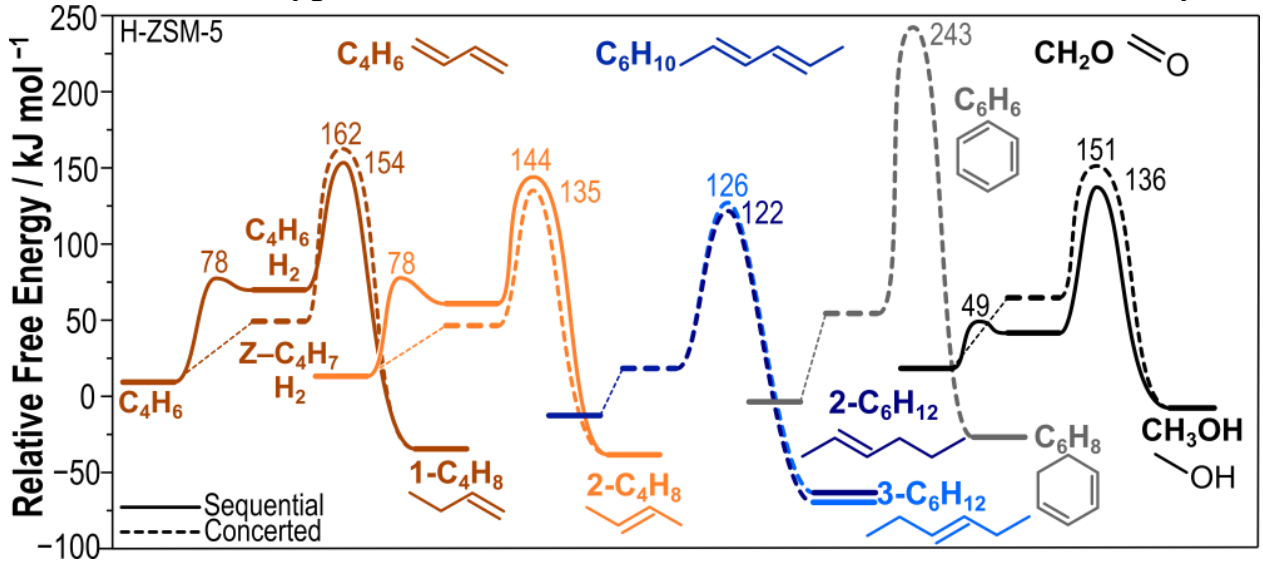

Figure 7. Reaction coordinate diagram of butadiene hydrogenation to 1-butene (brown) and 2-butene (orange), hexadiene hydrogenation to 2-hexene (dark blue) and 3-hexene (light blue), benzene (gray), and formaldehyde 
(black) via concerted (dashed) and sequential (solid) mechanisms. Free energies $\left(\mathrm{kJ} \mathrm{mol}^{-1}\right.$ ) are reported at $623 \mathrm{~K}$. All enthalpy, entropy, and free energy barriers are reported in Table S3 and transition state structures are shown in Section S7.

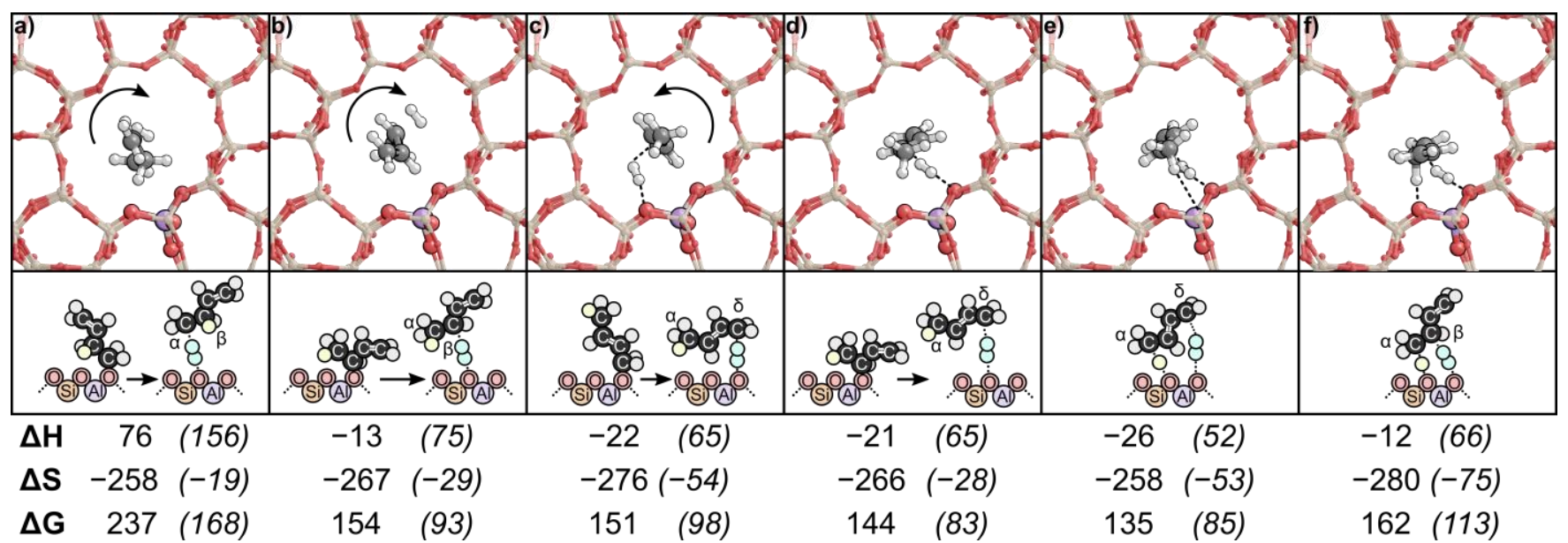

Figure 8. Most favorable transition state structures of a) sequential butadiene to 1-butene via a $\beta$-bound surface intermediate, b) sequential butadiene to 1-butene via an $\alpha$-bound surface intermediate, c) sequential butadiene to 2-butene via an $\alpha$-bound surface intermediate, $\mathrm{f} d$ ) sequential butadiene to 2-butene via a $\beta$-bound surface intermediate, e) concerted hydrogenation of butadiene to 2-butene, f) concerted hydrogenation of butadiene to 1butene. Effective and intrinsic (italics, parentheses) free energy barriers are reported in $\mathrm{kJ} \mathrm{mol}^{-1}$ at $623 \mathrm{~K}$. Yellow and blue shaded $\mathrm{H}$-atoms represent those from the zeolite and $\mathrm{H}_{2}$, respectively.

Hexadiene can hydrogenate to form 2-hexene via $\alpha, \beta$-attack (Fig. 9a) or 3-hexene via $\alpha, \delta$-attack (Fig. 9b). Protonated hexadiene is relatively stable $\left(\Delta \mathrm{G}\right.$ of $9 \mathrm{~kJ} \mathrm{~mol}^{-1}$ relative to gas phase species) because it forms an allylic carbocation coupled with long $\mathrm{C}_{6}$ chain; $\mathrm{C}_{2}-\mathrm{C}_{4}$ carbenium ions, in contrast, are unstable $\left(>100 \mathrm{~kJ}^{\mathrm{mol}}{ }^{-1}\right.$ relative to gas) when protonated. Moreover, the $\mathrm{Z}-\mathrm{C}_{6} \mathrm{H}_{11}$ species are unstable compared to the protonated state ( $\Delta \mathrm{G}$ of $46 \mathrm{~kJ} \mathrm{~mol}^{-1}$ relative to gas phase species), therefore, only the concerted mechanism was investigated for hexadiene species. Hexadiene hydrogenation transition states only involve heterolytic cleavage of $\mathrm{H}_{2}$ (Figs. 9a and $b$ ) rather than simultaneous protonation and hydridation as seen in $\mathrm{C}_{2}-\mathrm{C}_{4}$ compounds because of the stability of the carbocations formed renders means that the protonation is essentially complete prior to hydridation. However, hexadiene does not demonstrate a strong preference towards either $\alpha, \beta$ ( $\Delta \mathrm{G} \neq$ of $122 \mathrm{~kJ}^{\mathrm{mol}}{ }^{-1}$ to 2 hexene) or $\alpha, \delta$ ( $\Delta \mathrm{G} \neq 126 \mathrm{~kJ} \mathrm{~mol}^{-1}$ to 3-hexene) hydrogenation schemes. Barriers of hexadiene hydrogenation are $10-20 \mathrm{~kJ} \mathrm{~mol}^{-1}$ lower than those of butadiene, similar to trends observed in alkenes, - indicating that the longer chain length lowers hydrogenation barriers because of increased charge distribution across the carbon chain. 


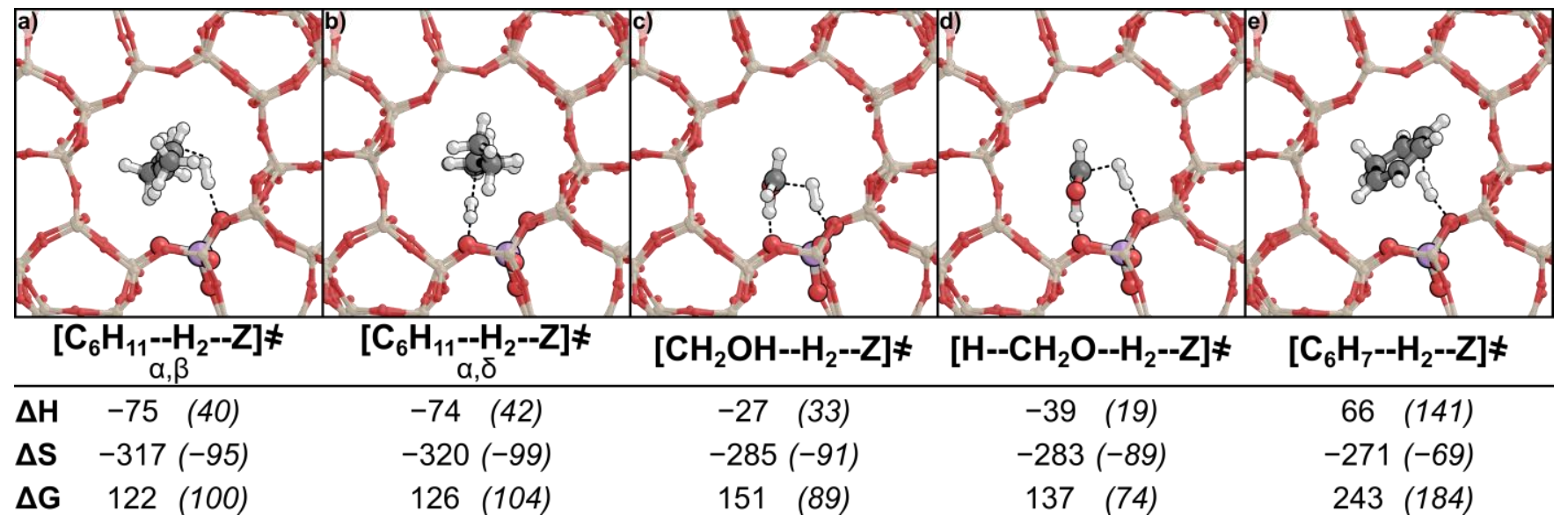

Figure 9. Most favorable transition states of hexadiene hydrogenation to a) 2-hexene and b) 3-hexene, c) Z$\mathrm{CH}_{2} \mathrm{OH}$ hydridation, d) concerted $\mathrm{CH}_{2} \mathrm{O}$ hydrogenation, and e) benzene hydridation. Effective and intrinsic (italics, parentheses) enthalpies $\left(\mathrm{kJ} \mathrm{mol}^{-1}\right)$, entropies $\left(\mathrm{J} \mathrm{K}^{-1} \mathrm{~mol}^{-1}\right)$, and free energies $\left(\mathrm{kJ} \mathrm{mol}^{-1}\right)$ are reported at $623 \mathrm{~K}$.

Previous literature has implicated $\mathrm{CH}_{2} \mathrm{O}$ as a precursor to dienes and aromatics and as a significant contributor to catalyst deactivation. ${ }^{26,44,67-69}$ Kinetic studies have demonstrated that co-feeding $\mathrm{H}_{2}$ and $\mathrm{CH}_{2} \mathrm{O}\left(4 \mathrm{bar}_{2}, 0.13\right.$ mbar $\mathrm{CH}_{2} \mathrm{O}, 0.13$ bar $\mathrm{CH}_{3} \mathrm{OH}, 673 \mathrm{~K}$ ) increases catalyst lifetimes by 2.1-fold compared to identical co-feeds of $\mathrm{He}$ and $\mathrm{CH}_{2} \mathrm{O}$. This indicates that $\mathrm{H}_{2}$ may limit polyaromatic formation by intercepting $\mathrm{CH}_{2} \mathrm{O}$ diene precursors. Therefore, we investigated $\mathrm{CH}_{2} \mathrm{O}$ hydrogenation in $\mathrm{MFI}$ and compare it to diene hydrogenation reactions to determine if deactivation is limited by direct hydrogenation of dienic species (i.e., arene precursors) or hydrogenation of diene precursors to prevent the initial formation of dienes. Concerted $\mathrm{CH}_{2} \mathrm{O}$ hydrogenation to form oxocarbeniums $\left(\mathrm{CH}_{2} \mathrm{OH}^{+}\right.$, Fig. 9d) via O-protonation is $>100 \mathrm{~kJ} \mathrm{~mol}^{-1}$ more favorable than C-protonation to form $\mathrm{CH}_{3} \mathrm{O}^{+}$. Similarly, the sequential mechanism involves formation and hydridation of a hydroxyalkoxide $\left(\mathrm{HOH}_{2} \mathrm{C}-\mathrm{Z}\right)$ (Fig. 9c). Hydrogenation of $\mathrm{CH}_{2} \mathrm{O}$ occurs with $\Delta \mathrm{G} \neq$ within $4 \mathrm{~kJ} \mathrm{~mol}^{-1}$ of butadiene at $623 \mathrm{~K}(140 \mathrm{~kJ}$ $\mathrm{mol}^{-1}$, Fig. 7), consistent with previous studies suggesting that barriers of $\mathrm{CH}_{2} \mathrm{O}$ hydrogenation are low compared to those of ethene hydrogenation. ${ }^{42}$ Despite the shorter chain length, these barriers are comparable to those of butadiene likely because of the relative stability of oxocarbenium ions (Fig. 2) coupled with hydrogen bonding between the framework and $-\mathrm{OH}$ of the transition state. This suggests that polyaromatic formation during MTO is limited by both direct diene hydrogenation and hydrogenation of diene precursor species.

The benzene hydrogenation transition state involves only heterolytic cleavage of $\mathrm{H}_{2}$ as protonated benzenium cations are relatively stable compared aliphatic carbenium ions. Moreover, $\mathrm{C}_{6} \mathrm{H}_{7}^{+}\left(\Delta \mathrm{G}\right.$ of $87 \mathrm{~kJ}^{\mathrm{mol}}{ }^{-1}$ relative to $^{+}$ gas phase species, Table S2) is significantly more stable than $\mathrm{Z}-\mathrm{C}_{6} \mathrm{H}_{7}$ species ( $\Delta \mathrm{G}$ of $341 \mathrm{~kJ} \mathrm{~mol}^{-1}$ relative to gas phase species, Table S2); therefore, alkoxide-formation and alkoxide-hydridation pathways were not considered for benzene. Free energy barriers associated benzene hydridation (243 kJ mol ${ }^{-1}$, Fig. 7) are significantly higher than all investigated alkenes and dienes, because breaking the aromaticity of the benzene ring results in unstable states. This is consistent with previous experimental studies suggesting that benzene does not react with hydrogen unless there are tertiary hydride sources present. ${ }^{40}$ Benzene hydrogenation routes are insignificant at high $\mathrm{H}_{2}$ MTO conditions, so arene hydrogenation does not contribute to decreases in deactivation rates in MFI. ${ }^{37,38}$ Rather, the formation of polyaromatics is limited through elimination of $\mathrm{CH}_{2} \mathrm{O}$ and dienes.

\subsection{Hydrogenation in H-CHA (H-SSZ-13)}

Concerted and sequential hydrogenation reactions were also investigated in CHA zeolites, which is topologically distinct from MFI. MFI contains straight and sinusoidal channels that intersect to form the channel intersection, where T11 is situated, and the three accessible O-sites of T11 reside in the straight channel (O14) or 
bridge straight channel and channel intersection (O16 and $\mathrm{O} 25)$. This work, and previous work, ${ }^{61}$ have demonstrated that the straight channel of H-ZSM-5 (MFI) offers confinement for smaller transition states, such as those associated with the hydrogenation of small molecules like those investigated here. Conversely, the Osites of H-SSZ-13 (CHA) each have different chemical environments: O1 bridges a 6 membered-ring (6-MR) and two 4-MRs, O2 spans two 8-MRs, O3 spans the 6-MR and 8-MR, and O4 spans the 8-MR and 4-MR (Fig. S2). Similar to MFI, hydrogenation of $\mathrm{C}_{2}-\mathrm{C}_{4}$ alkenes, $\mathrm{C}_{4}$ and $\mathrm{C}_{6}$ dienes, benzene, and $\mathrm{CH}_{2} \mathrm{O}$ was investigated at all $\mathrm{O}-$ site combinations within CHA.

Alkene hydrogenation in H-SSZ-13 (Fig. 10) occurs with similar trends as observed in MFI. Maximum rate analysis is used to identify the rate-determining step of the sequential mechanism and rates of alkoxide hydridation are $>400 \times$ lower $\left(553-723 \mathrm{~K}, 1-20\right.$ bar $\mathrm{H}_{2}, 0.01-0.15$ bar reactant, Fig. S5 of the SI) than rates of alkoxide formation; therefore, alkoxide hydridation is kinetically relevant (as observed for MFI) and the remainder of this discussion will focus on comparing alkoxide hydridation (of the sequential mechanism) and the concerted mechanism. There are two distinct alkoxide hydrogenation transition states: heterolytic $\mathrm{H}_{2}$ cleavage (Figs. $11 \mathrm{~b}$ and d, bottom) or alkoxide rotation (Figs. 11a and c, bottom). The instability of primary carbocations causes an earlier transition state that includes rotation whereas transition states of secondary carbocations primarily involve heterolytic cleavage of $\mathrm{H}_{2}$. Alkene hydrogenation barriers in H-SSZ-13 (Fig. 10) are consistently 5-15 kJ mol ${ }^{-1}$ lower than those in H-ZSM-5 (Fig. 4), indicating that the topology of H-SSZ-13 stabilizes alkylcarbeniums slightly better than MFI. This is corroborated by experimental results showing that $\mathrm{H}_{2}$ co-feeds $\left(16\right.$ bar $\mathrm{H}_{2}, 0.13$ bar $\mathrm{CH}_{3} \mathrm{OH}, 673 \mathrm{~K}$ ) increase turnover by a greater extent $(4.5 \times)$ in H-SSZ-13 (H-CHA) than in H-ZSM-5 (3×, MFI) catalysts. ${ }^{37}$

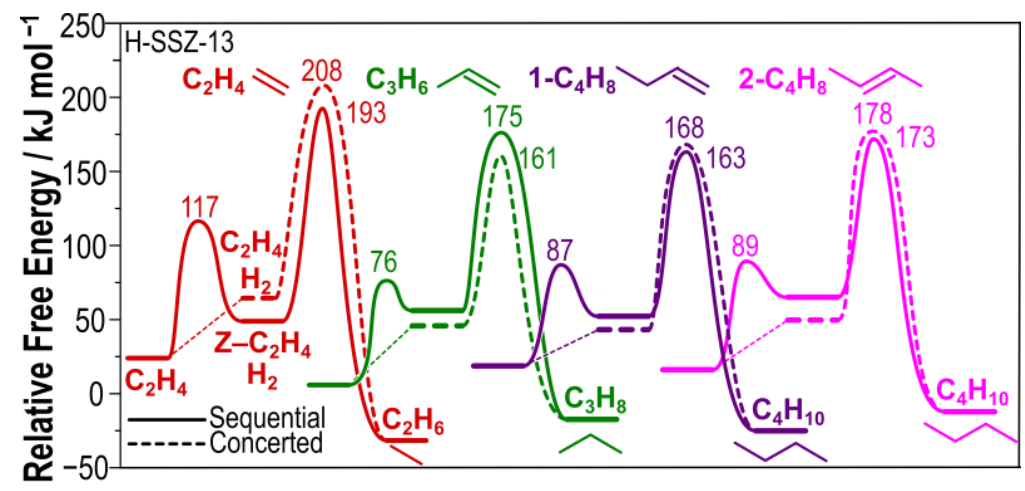

Figure 10. Free energy barriers of ethene (red), propene (green), 1-butene (purple), and 2-butene (pink) concerted (dashed) and sequential (solid) hydrogenation barriers in CHA. Free energies $\left(\mathrm{kJ} \mathrm{mol}^{-1}\right)$ are reported at $623 \mathrm{~K}$ and 1 bar of each species (alkene and $\mathrm{H}_{2}$ ). All enthalpy, entropy, and free energy barriers are reported in Table S4 and transition state structures are shown in Section S7. 


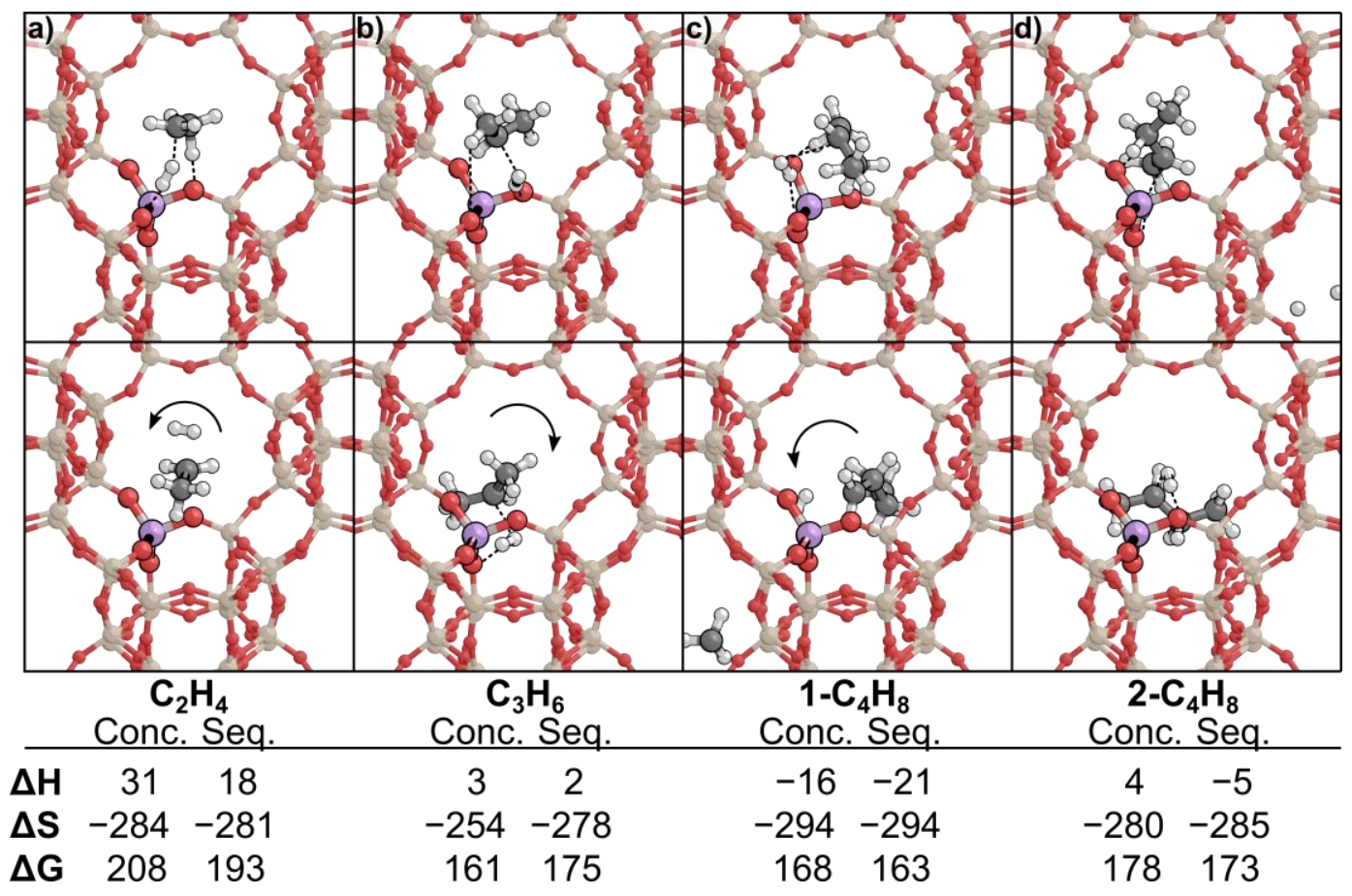

Figure 11. Most favorable concerted (top) and sequential (bottom) transition states of a) ethene, b) propene, c) 1butene, and d) 2-butene. Enthalpies $\left(\mathrm{kJ} \mathrm{mol}^{-1}\right)$, entropies $\left(\mathrm{J} \mathrm{K}^{-1} \mathrm{~mol}^{-1}\right)$, and free energies $\left(\mathrm{kJ} \mathrm{mol}^{-1}\right)$ are reported relative to the gas phase energies at $623 \mathrm{~K}$.

Barriers of butadiene hydrogenation (150 and $152 \mathrm{~kJ} \mathrm{~mol}^{-1}$, Fig. 12) are lower than those of alkene hydrogenation (161-193 $\mathrm{kJ} \mathrm{mol}^{-1}$, Fig. 10)—indicating that butadiene hydrogenation occurs preferentially over alkene hydrogenation in H-SSZ-13 (CHA). DFT-predicted rate constants suggest that rates of butadiene hydrogenation are $\sim 76 \times$ those of propene hydrogenation and $1000 \times$ higher than ethene hydrogenation (Fig. S6). Kinetic studies co-feeding 1,3-butadiene (H-CHA (H-SSZ-13), 1-16 bar $\mathrm{H}_{2}, 0.1-1$ mbar $\mathrm{C}_{2} \mathrm{H}_{4}$ or $\mathrm{C}_{3} \mathrm{H}_{6}$ or $\mathrm{C}_{4} \mathrm{H}_{6}$, $673 \mathrm{~K}$ ) predict that butadiene hydrogenation rates are 185 -fold higher than propene hydrogenation and 263 -fold higher than ethene hydrogenation in H-SSZ-13, ${ }^{39}$ indicating that the relative rates as predicted by DFT are within factors of 3 of measured relative rates. Unlike MFI, barriers to form 2-butene are not significantly favored over 1-butene formation ( $4 \mathrm{~kJ} \mathrm{~mol}^{-1}$ in H-SSZ-13 compared to $19 \mathrm{~kJ} \mathrm{~mol}^{-1}$ in H-ZSM-5), suggesting that the $\alpha, \delta$ versus $\alpha, \beta$ hydrogenation schemes do not play a significant role in determining hydrogenation product selectivity in CHA as seen in MFI. As such, it is likely that CHA zeolites form a mixture of butene isomers during the hydrogenation process.

Similar to MFI, hexadiene hydrogenation barriers are lower than those of butadiene barriers, because longer C-chains facilitate charge distribution. Unlike MFI, CHA demonstrates a stronger preference to form 3-hexene via $\alpha, \delta$ hydrogenation of hexadiene (by $17 \mathrm{~kJ} \mathrm{~mol}^{-1}$ ) over $\alpha, \beta$ hydrogenation to form 2-hexene-likely caused by differences in local topologies between the two frameworks shifting product selectivity. Benzene hydrogenation is unfavorable and barriers for $\mathrm{CH}_{2} \mathrm{O}$ hydrogenation $\left(\Delta \mathrm{G} \neq\right.$ of $138 \mathrm{~kJ} \mathrm{~mol}^{-1}$ and $146 \mathrm{~kJ} \mathrm{~mol}^{-1}$, Fig. 12) are lower than those of alkene hydrogenation $\left(\Delta \mathrm{G} \neq\right.$ of $161 \mathrm{~kJ} \mathrm{~mol}^{-1}-193 \mathrm{~kJ} \mathrm{~mol}^{-1}$ ), consistent with previous DFTpredictions ${ }^{42}$ Furthermore, $\mathrm{CH}_{2} \mathrm{O}$ hydrogenation barriers are lower than those of butadiene hydrogenation $(\Delta \mathrm{G} \neq$ of $150 \mathrm{~kJ} \mathrm{~mol}^{-1}$ ), indicating $\mathrm{CH}_{2} \mathrm{O}$ elimination may play a more critical role in CHA frameworks as compared to MFI frameworks. Therefore, deactivation in H-SSZ-13 is likely prevented through both direct hydrogenation of dienes and hydrogenation of $\mathrm{CH}_{2} \mathrm{O}$ to prevent diene formation, rather than elimination of aromatic species. 


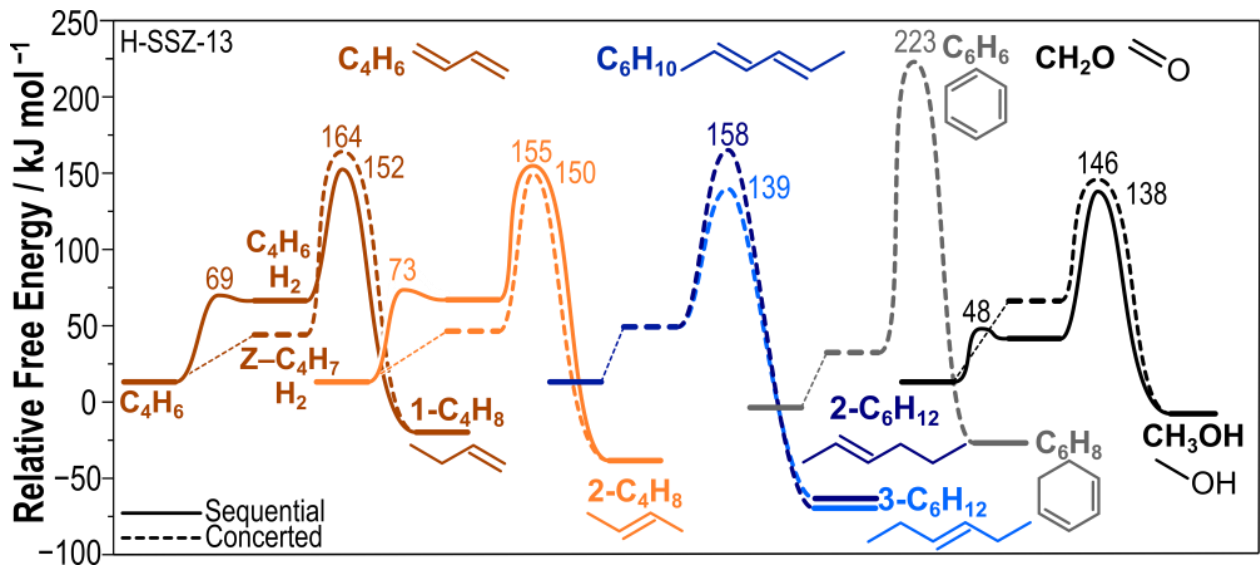

Figure 12. Reaction coordinate diagram of butadiene hydrogenation to 1-butene (brown) and 2-butene (orange), hexadiene hydrogenation to 2-hexene (dark blue) and 3-hexene (light blue), benzene (gray), and formaldehyde (black) via concerted (dashed) and sequential (solid) mechanisms. Free energies $\left(\mathrm{kJ} \mathrm{mol}^{-1}\right)$ are reported at $623 \mathrm{~K}$. All enthalpy, entropy, and free energy barriers are reported in Table S4 and transition state structures are shown in Section S7.

\subsection{Hydrogenation in H-SAPO-34 (CHA Framework)}

High $\mathrm{H}_{2}$ cofeeds have been shown to increase catalyst lifetime in H-SAPO-34 by a factor of 10 (673 K, 4 bar $\mathrm{H}_{2}, 0.13$ bar $\mathrm{CH}_{3} \mathrm{OH}$ ) demonstrating that high $\mathrm{H}_{2}$ co-feeds can increase catalyst lifetimes in a variety of different zeolite framework topologies. Here, we will compare trends in transition state energy barriers in H-SSZ-13 and H-SAPO-34 to determine the effects of acid strength on hydrogenation pathways.

Trends in sequential and concerted hydrogenation are similar to those observed in H-ZSM-5 (Section 3.2) and H-SSZ-13 (Section 3.3); therefore, this discussion will focus primarily on hydrogenation of butene, dienes, and $\mathrm{CH}_{2} \mathrm{O}$. The $\alpha, \delta$-attack mechanism of butadiene is $9 \mathrm{~kJ} \mathrm{~mol}^{-1}$ more favorable than comparable $\alpha, \beta$-attack mechanisms (Fig. 13). Notably, unlike H-SSZ-13 and H-ZSM-5, $\mathrm{CH}_{2} \mathrm{O}$ hydrogenation barriers are significantly lower than those of both butadiene and hexadiene. This increased favorability towards $\mathrm{CH}_{2} \mathrm{O}$ hydrogenation in $\mathrm{H}-\mathrm{SAPO}-34$ is likely because $\mathrm{Al}-\mathrm{O}$ bonds are more polar than $\mathrm{Si}-\mathrm{O}$ bonds lending to increased hydrogen bonding between the $\mathrm{CH}_{2} \mathrm{O}$ transition state and zeolite framework. This suggests that deactivation in H-SAPO-34 is primarily limited by hydrogenation of $\mathrm{CH}_{2} \mathrm{O}$, or diene precursors, to prevent formation of dienic compounds; rather than elimination of both dienes and diene precursors as observed in H-ZSM-5 and H-SSZ-13.

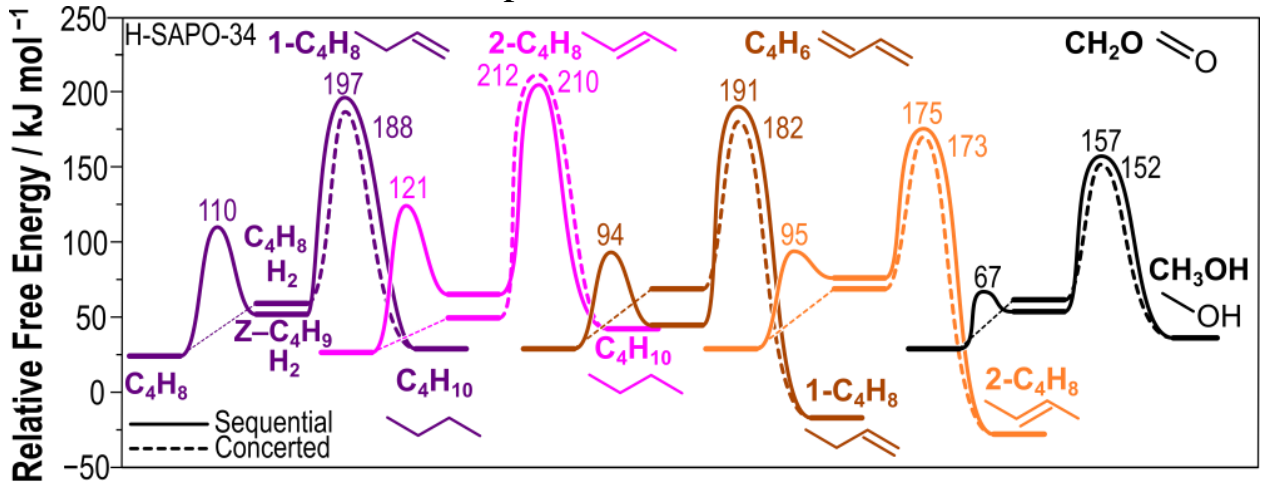

Figure 13. Reaction coordinate diagram of 1-butene (orange) and 2-butene (gray) hydrogenation to butadiene, butadiene hydrogenation to 1-butene (yellow) and 2-butene (blue), hexadiene hydrogenation to 2-hexene (green) and 3-hexene (dark blue), and formaldehyde (blue) via concerted mechanisms. Free energies ( $\mathrm{kJ}^{\mathrm{mol}}{ }^{-1}$ ) are reported at $623 \mathrm{~K}$. All enthalpy, entropy, and free energy barriers are reported in Table S5 and transition state structures are shown in Section S7. 
Generally, trends amongst the aluminosilicate frameworks (H-ZSM-5 and H-SSZ-13) and phosphoaluminosilicate framework (H-SAPO-34) are similar (Fig. 14). Hydrogenation barriers decrease as the length of the carbon-chain increases for both alkenes and dienes in all three zeotype catalysts. Butadiene hydrogenation is facilitated by forming an allylic carbocation (Fig. 14) and preferentially forms 2-butene instead of 1-butene in all zeotypes - indicating that the $\alpha, \delta$ hydrogenation scheme may play a role in its relatively low barriers. Formaldehyde hydrogenates with similar barriers to butadiene, as described below, and benzene hydrogenates with barriers significantly larger than those for all other species.

Comparing the two aluminosilicates (in CHA and MFI), hydrogenation free energy barriers (relative to gasphase species) are generally similar (most are within $12 \mathrm{~kJ} \mathrm{~mol}^{-1}$ of one another) with H-SSZ-13 (CHA) having slightly lower barriers, on average, than H-ZSM-5 (MFI). Effective free energy barriers for hydrogenation reactions in H-SAPO-34 are 12-38 $\mathrm{kJ} \mathrm{mol}^{-1}$ higher than in H-SSZ-13 (Fig. 15) - indicating that the decreased acid strength of H-SAPO-34 results in lower hydrogenation rates and that this effect is approximately even across hydrocarbon molecules and mechanisms studied here. $\mathrm{C}_{6} \mathrm{H}_{10}$ and $\mathrm{CH}_{2} \mathrm{O}$ hydrogenation barriers are just 12 and 16 $\mathrm{kJ} \mathrm{mol}^{-1}$ higher, respectively, the least destabilized by the decreased acid strength, likely because these species hydrogenate through relatively stable carbocations compared to others. These trends are consistent with previous studies using DFT (BEEF-vdw) that compared alkene formation routes in H-SSZ-13 and H-SAPO-34 which indicate that barriers in H-SAPO-34 are $10-20 \mathrm{~kJ} \mathrm{~mol}^{-1}$ higher than those in H-SSZ-13. ${ }^{70}$

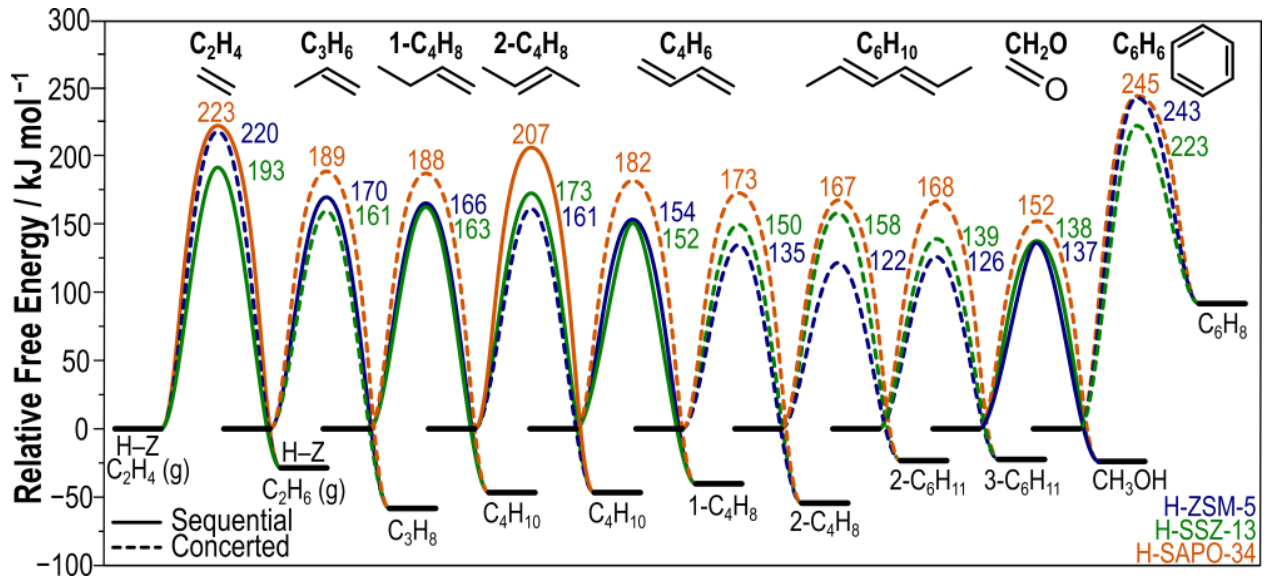

Figure 14. Hydrogenation energies relative to gas phase species in H-ZSM-5 (MFI, blue), H-SSZ-13 (CHA, green), and H-SAPO-34 (CHA, orange). Fig. S7 of the SI shows the same data generated using the BEEF-vdW functional.

Formaldehyde hydrogenates with barriers $7 \mathrm{~kJ} \mathrm{~mol}^{-1}$ higher than butadiene in H-ZSM-5 and with barriers 9 and $16 \mathrm{~kJ} \mathrm{~mol}^{-1}$ lower than butadiene in H-SSZ-13 and H-SAPO-34, respectively. As such, hydrogenation of diene precursors $\left(\mathrm{CH}_{2} \mathrm{O}\right)$ may also play a key role in increasing catalyst lifetimes, perhaps more so in $\mathrm{CHA}$ frameworks. Prior reports, ${ }^{57}$ however, have indicated that formaldehyde hydrogenation barriers are underestimated with PBE-D3 compared to CCSD methods applied to cluster models, and that the BEEF-vdW functional give better agreement with those CCSD methods. Trends between zeolite frameworks and hydrogenation barriers remain consistent in our BEEF-vdW calculations (Fig. S7). BEEF-vdW free energies of hydrocarbon hydrogenation tend to be within $\sim 10 \mathrm{~kJ} \mathrm{~mol}^{-1}$ of PBE-D3 obtained free energies, with a few exceptions. Generally, the conclusions one would reach using the BEEF-vdW functional would be the same as those reached here; that $\mathrm{H}_{2}$ extends catalyst lifetimes through a combination of diene and formaldehyde 
hydrogenation, with relative rates of those pathways being dictated by the relative concentrations of those species in the zeolite during MTO reactions; which itself depends on many factors.

\subsection{Effects of $\mathrm{H}_{2} \mathrm{O}$}

The effects of $\mathrm{H}_{2} \mathrm{O}$ on hydrogenation barriers was investigated as recent studies have demonstrated that cofeeding high pressures of $\mathrm{H}_{2}$ and $\mathrm{H}_{2} \mathrm{O}$ further increases catalyst lifetimes from 75 hours $\left(4.2\right.$ bar $\mathrm{CH}_{3} \mathrm{OH}, 35.7$ bar $\mathrm{H}_{2}, 723 \mathrm{~K}$ ) to 118 hours (4.2 bar $\mathrm{CH}_{3} \mathrm{OH}, 22.8$ bar $\mathrm{H}_{2}, 12.8$ bar $\mathrm{H}_{2} \mathrm{O}, 723 \mathrm{~K}$ ) as measured by the time at which methanol conversion dips beneath $80 \% .{ }^{38}$ Concerted hydrogenation of 2-butene, butadiene, and $\mathrm{CH}_{2} \mathrm{O} \mathrm{was}$ modeled with $\mathrm{H}_{2} \mathrm{O}$ in all three zeolite catalysts (Figs. 15a-c) to determine if $\mathrm{H}_{2} \mathrm{O}$ facilitates hydrogenation reactions by lowering free energy barriers by facilitating protonation. The transition state is remarkably similar in all three frameworks and involves $\mathrm{H}_{2} \mathrm{O}$ facilitating proton transfer and stabilizing the carbocation with simultaneous hydridation of the guest species by $\mathrm{H}_{2}$. The increased hydrogen bonding in the transition state lowers effective enthalpy barriers $(\Delta \mathrm{H} \neq)$ by $34-97 \mathrm{~kJ} \mathrm{~mol}^{-1}$ compared to routes without $\mathrm{H}_{2} \mathrm{O}$. This indicates that $\mathrm{H}_{2} \mathrm{O}$ can enthalpically stabilize these transition state formations by interacting with the carbocation and conjugate base of the acid site, however, it does so by sacrificing significant entropy compared to gas-phase $\mathrm{H}_{2} \mathrm{O}$. The entropic losses outweigh the enthalpic gains in the free energies as all transition states facilitated by $\mathrm{H}_{2} \mathrm{O}$ occur with $\Delta \mathrm{G} \neq$ of 5-40 kJ mol ${ }^{-1}$ higher than transition states with just $\mathrm{H}_{2}$ (Fig. 15d). This indicates that $\mathrm{H}_{2} \mathrm{O}$ does not directly facilitate hydrogenation reactions except at very high $\mathrm{H}_{2} \mathrm{O}: \mathrm{H}_{2}$ ratios; rather, increased lifetimes with $\mathrm{H}_{2} \mathrm{O}$ pressures are likely caused by an increase in the number of available protons via $\mathrm{CH}_{3}-\mathrm{Z}+\mathrm{H}_{2} \mathrm{O} \rightarrow \mathrm{H}-\mathrm{Z}+\mathrm{CH}{ }_{3} \mathrm{OH}$ reactions which remove surface methyl species. If surface methylation is rapid and quasi-equilibrated, then the concentration of methyl species is inversely proportional to $\mathrm{H}_{2} \mathrm{O}$ pressure, and thus proton coverages and therefore hydrogenation rates increase with $\mathrm{H}_{2} \mathrm{O}$ pressure, as observed.
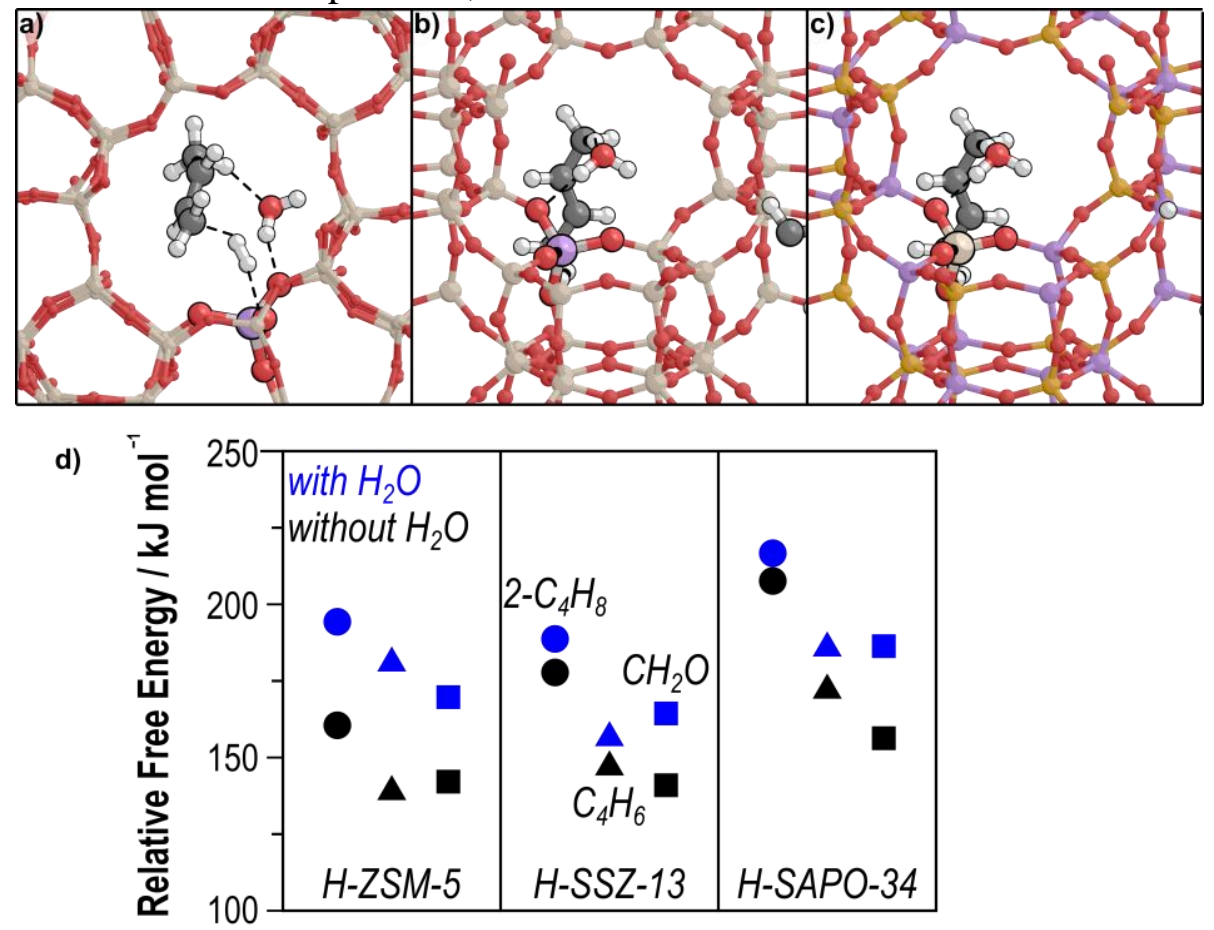

Figure 15. Images of $\mathrm{H}_{2} \mathrm{O}$ assisted concerted butadiene transition state in a) $\mathrm{H}-\mathrm{ZSM}-5$ (MFI), b) H-SSZ-13 (CHA), and c) H-SAPO-34 (CHA), and d) shows relative free energies concerted 2-butene ( $\bullet$ ), butadiene (ם), and formaldehyde $(\boldsymbol{\Delta})$ hydrogenation with $\mathrm{H}_{2} \mathrm{O}$ (blue) and without $\mathrm{H}_{2} \mathrm{O}$ (black). Free energies are reported at $623 \mathrm{~K}$ and 1 bar of all reactants. Entropy and enthalpy barriers are tabulated in Table S6 of the SI.

\section{Conclusions}


Here, we investigate concerted and sequential diene hydrogenation schemes for $\mathrm{C}_{2}-\mathrm{C}_{4}$ alkenes, $\mathrm{C}_{4}$ and $\mathrm{C}_{6}$ dienes, benzene, and $\mathrm{CH}_{2} \mathrm{O}$ to determine the mechanism by which high pressure $\mathrm{H}_{2}$ co-feeds improve catalyst lifetime. Barriers and DFT-predicted rates for sequential and concerted hydrogenation are within the errors of DFT methods in all cases, indicating that the two hydrogenation mechanisms compete during catalysis and cannot be distinguished using theory or isotopic studies. For both mechanisms, the limiting portion of the reaction is the heterolytic $\mathrm{H}_{2}$ dissociation that transfers a hydride to a carbocation. Generally, hydrogenation barriers in the aluminosilicate two frameworks H-SSZ-13 and H-ZSM-5 (CHA and MFI) are within $15 \mathrm{~kJ} \mathrm{~mol}^{-1}$ of one another and hydrogenation barriers follow nearly identical trends between the two frameworks, despite the different confining void topologies. Additionally, the effects of interchanging the aluminosilicate CHA framework (HSSZ-13) with phosphoaluminosilicate CHA framework (H-SAPO-34) results in systematic increases of hydrogenation barriers by $20-30 \mathrm{~kJ} \mathrm{~mol}^{-1}$ caused by the weaker acid site in H-SAPO-34.

Alkene hydrogenation proceeds via the formation of secondary alkylcarbenium ions, when possible, over primary carbenium ions which are less stable (by $20-70 \mathrm{~kJ} \mathrm{~mol}^{-1}$ ), resulting in lower barriers for $\mathrm{C}_{3}$ and $\mathrm{C}_{4}$ alkenes compared to $\mathrm{C}_{2}$ hydrogenation. Oxocarbenium ions formed in $\mathrm{CH}_{2} \mathrm{O}$ hydrogenation are stable and result in low hydrogenation barriers, however, stable benzenium carbocations cannot overcome the thermodynamic instability of benzene hydrogenation, resulting in large benzene hydrogenation barriers. Allylic carbocations are formed during diene hydrogenations and are more stable than alkylcarbenium cations (formed in alkene hydrogenations), and hydrogenation of dienes is further accelerated by increasing carbon-chain length as hydrogenation barriers of hexadiene are $10-20 \mathrm{~kJ} \mathrm{~mol}^{-1}$ lower than those of butadiene.

The main mechanism of lifetime improvement is through limiting the formation of deactivation precursorsdienes and $\mathrm{CH}_{2} \mathrm{O}$. Direct hydrogenation barriers of butadiene are relatively low $\left(135 \mathrm{~kJ} \mathrm{~mol}^{-1}\right.$ in $\mathrm{ZSM}-5,150 \mathrm{~kJ}$ $\mathrm{mol}^{-1}$ in SSZ-13, and $173 \mathrm{~kJ} \mathrm{~mol}^{-1}$ in SAPO-34), as are those of hydrogenation of $\mathrm{CH}_{2} \mathrm{O}$, which plays a role in diene formation ${ }^{26,44}\left(137 \mathrm{~kJ} \mathrm{~mol}^{-1}\right.$ in ZSM-5, $138 \mathrm{~kJ} \mathrm{~mol}^{-1}$ in SSZ-13, and $152 \mathrm{~kJ} \mathrm{~mol}^{-1}$ in SAPO-34), with similar barriers found for the PBE-D3 and BEEF-vdW functionals. The limited hydrogenation of alkenes alongside increases in catalyst lifetime in MTO studies suggest that deactivation precursors must be selectively hydrogenated (i.e., hydrogenated at a higher rate) than the desired alkene products, and this is proven here as diene and formaldehyde hydrogenation occurs with barriers $15-26 \mathrm{~kJ} \mathrm{~mol}^{-1}$ lower than those for propene or butene hydrogenation and $43-85 \mathrm{~kJ} \mathrm{~mol}^{-1}$ lower than those for ethene hydrogenation. This indicates that dienes and $\mathrm{CH}_{2} \mathrm{O}$ are selectively hydrogenated over alkenes, consistent with previous kinetic studies suggesting that rate constants of butadiene hydrogenation are higher than those of $\mathrm{C}_{2}$ and $\mathrm{C}_{3}$ alkene hydrogenation. ${ }^{39}$ Overall, hydrogenation of dienes and $\mathrm{CH}_{2} \mathrm{O}$ is relatively facile compared alkenes in MFI and CHA zeolite frameworks demonstrating that diene prevention and elimination is the primary mechanism of catalyst lifetime improvement with high-pressure $\mathrm{H}_{2}$ co-feeds.

\section{Associated Content}

Supporting Information. Structures of reactant product, and transition states, detailed analysis of hydrogenation rates, formulas and details of frequency calculations for enthalpy and free energy approximations, kinetic isotope effects, and all activation and reaction enthalpies and entropies.

Acknowledgements. This work was funded by an ACS Petroleum Research Fund New Doctoral Investigation Award (57079-DNI5). Partial support was provided by the NSF REU site grant (1852111) and the Summer Undergraduate Research at Florida (SURF) program. Computational resources were provided by the Extreme Science and Engineering Discovery Environment (XSEDE), ${ }^{78}$ which is supported by National Science Foundation 
grant number ACI-1548562 through allocation CTS160041. Additional computational resources were provided by University of Florida Research Computing. 


\section{References}

(1) Ilias, S.; Bhan, A. Mechanism of the catalytic conversion of methanol to hydrocarbons. ACS Catal. 2013, 3, 18-31 DOI: 10.1021/cs3006583.

(2) Haw, J. F.; Song, W.; Marcus, D. M.; Nicholas, J. B. The mechanism of methanol to hydrocarbon catalysis. Acc. Chem. Res. 2003, 36, 317-326 DOI: 10.1021/ar020006o.

(3) Avidan, A. A. Gasoline and distillate fuels from methanol. In Methane Conversion, Proceedings of a Symposium on the Production of Fuels and Chemicals from Natural Gas; Studies in surface science and catalysis; Elsevier, 1988; Vol. 36, pp. 307-323.

(4) Blaszkowski, S. R.; van Santen, R. A. Theoretical Study of C-C Bond Formation in the Methanol-toGasoline Process. J. Am. Chem. Soc. 1997, 119, 5020-5027 DOI: 10.1021/ja963530x.

(5) Chang, C. D.; Kuo, J. C. W.; Lang, W. H.; Jacob, S. M.; Wise, J. J.; Silvestri, A. J. Process studies on the conversion of methanol to gasoline. Ind. Eng. Chem. Proc. Des. Dev. 1978, 17, 255-260 DOI: 10.1021/i260067a008.

(6) Johansson, R.; Hruby, S. L.; Rass-Hansen, J.; Christensen, C. H. The Hydrocarbon Pool in Ethanol-toGasoline over HZSM-5 Catalysts. Catal. Lett 2009, 127, 1-6 DOI: 10.1007/s10562-008-9711-2.

(7) Olsbye, U.; Svelle, S.; Lillerud, K. P.; Wei, Z. H.; Chen, Y. Y.; Li, J. F.; Wang, J. G.; Fan, W. B. The formation and degradation of active species during methanol conversion over protonated zeotype catalysts. Chem. Soc. Rev. 2015, 44, 7155-7176 DOI: 10.1039/c5cs00304k.

(8) Hwang, A.; Bhan, A. Deactivation of Zeolites and Zeotypes in Methanol-to-Hydrocarbons Catalysis: Mechanisms and Circumvention. Acc. Chem. Res. 2019 DOI: 10.1021/acs.accounts.9b00204.

(9) Rojo-Gama, D.; Signorile, M.; Bonino, F.; Bordiga, S.; Olsbye, U.; Lillerud, K. P.; Beato, P.; Svelle, S. Structure-deactivation relationships in zeolites during the methanol-to-hydrocarbons reaction:

Complementary assessments of the coke content. J. Catal. 2017, 351, 33-48 DOI: 10.1016/j.jcat.2017.04.015.

(10) Rojo-Gama, D.; Nielsen, M.; Wragg, D. S.; Dyballa, M.; Holzinger, J.; Falsig, H.; Lundegaard, L. F.; Beato, P.; Brogaard, R. Y.; Lillerud, K. P.; et al. A Straightforward Descriptor for the Deactivation of Zeolite Catalyst H-ZSM-5. ACS Catal. 2017, 7, 8235-8246 DOI: 10.1021/acscatal.7b02193.

(11) Li, J.; Wei, Y.; Qi, Y.; Tian, P.; Li, B.; He, Y.; Chang, F.; Sun, X.; Liu, Z. Conversion of methanol over H-ZSM-22: The reaction mechanism and deactivation. Catal. Today 2011, 164, 288-292 DOI: 10.1016/j.cattod.2010.10.095.

(12) Müller, S.; Liu, Y.; Vishnuvarthan, M.; Sun, X.; van Veen, A. C.; Haller, G. L.; Sanchez-Sanchez, M.; Lercher, J. A. Coke formation and deactivation pathways on H-ZSM-5 in the conversion of methanol to olefins. J. Catal. 2015, 325, 48-59 DOI: 10.1016/j.jcat.2015.02.013.

(13) Guisnet, M.; Costa, L.; Ribeiro, F. R. Prevention of zeolite deactivation by coking. J. Mol. Catal. A: Chem 2009, 305, 69-83 DOI: 10.1016/j.molcata.2008.11.012.

(14) Dejaifve, P.; Védrine, J. C.; Bolis, V.; Derouane, E. Reaction pathways for the conversion of methanol and olefins on H-ZSM-5 zeolite. J. Catal. 1980, 63, 331-345 DOI: 10.1016/0021-9517(80)90086-X.

(15) Wang, S.; Chen, Y.-Y.; Wei, Z.; Qin, Z.; Ma, H.; Dong, M.; Li, J.; Fan, W.; Wang, J. Polymethylbenzene or Alkene Cycle? Theoretical Study on Their Contribution to the Process of Methanol to Olefins over H-ZSM-5 Zeolite. J. Phys. Chem. C 2015, 119, 28482-28498.

(16) Wang, C.-M.; Wang, Y.-D.; Liu, H.-X.; Yang, G.; Du, Y.-J.; Xie, Z.-K. Aromatic-based hydrocarbon pool mechanism for methanol-to-olefins conversion in H-SAPO-18: A van der Waals density functional study. Chinese Journal of Catalysis 2015, 36, 1573-1579 DOI: 10.1016/S1872-2067(15)60891-9. 
(17) Hwang, A.; Prieto-Centurion, D.; Bhan, A. Isotopic tracer studies of methanol-to-olefins conversion over HSAPO-34: The role of the olefins-based catalytic cycle. J. Catal. 2016, 337, 52-56 DOI:

10.1016/j.jcat.2016.01.021.

(18) Sun, X.; Mueller, S.; Shi, H.; Haller, G. L.; Sanchez-Sanchez, M.; van Veen, A. C.; Lercher, J. A. On the impact of co-feeding aromatics and olefins for the methanol-to-olefins reaction on HZSM-5. J. Catal.

2014, 314, 21-31 DOI: 10.1016/j.jcat.2014.03.013.

(19) Wang, C.-M.; Wang, Y.-D.; Xie, Z.-K. Verification of the dual cycle mechanism for methanol-to-olefin conversion in HSAPO-34: a methylbenzene-based cycle from DFT calculations. Catal. Sci. Technol.

2014, 4, 2631-2638 DOI: 10.1039/C4CY00262H.

(20) Hill, I. M.; Hashimi, S. A.; Bhan, A. Kinetics and mechanism of olefin methylation reactions on zeolites. J. Catal. 2012, 285, 115-123 DOI: 10.1016/j.jcat.2011.09.018.

(21) Svelle, S.; Joensen, F.; Nerlov, J.; Olsbye, U.; Lillerud, K.-P.; Kolboe, S.; Bjørgen, M. Conversion of methanol into hydrocarbons over zeolite H-ZSM-5: ethene formation is mechanistically separated from the formation of higher alkenes. J. Am. Chem. Soc. 2006, 128, 14770-14771 DOI: 10.1021/ja065810a.

(22) Wilhelmsson, B. Formaldehyde. Rhinology 1985, 23, 128-129.

(23) Wang, S.; Agirrezabal-Telleria, I.; Bhan, A.; Simonetti, D.; Takanabe, K.; Iglesia, E. Catalytic routes to fuels from C1 and oxygenate molecules. Faraday Discuss 2017, 197, 9-39 DOI: 10.1039/c7fd00018a.

(24) Hwang, A.; Kumar, M.; Rimer, J. D.; Bhan, A. Implications of methanol disproportionation on catalyst lifetime for methanol-to-olefins conversion by HSSZ-13. J. Catal. 2017, 346, 154-160 DOI: 10.1016/j.jcat.2016.12.003.

(25) Lukyanov, D. B.; Gnep, N. S.; Guisnet, M. R. Kinetic modeling of ethene and propene aromatization over HZSM-5 and GaHZSM-5. Ind Eng Chem Res 1994, 33, 223-234 DOI: 10.1021/ie00026a008.

(26) Lukyanov, D. B.; Gnep, N. S.; Guisnet, M. R. Kinetic modeling of propane aromatization reaction over HZSM-5 and GaHZSM-5. Ind Eng Chem Res 1995, 34, 516-523 DOI: 10.1021/ie00041a012.

(27) Joshi, Y. V.; Thomson, K. T. Brønsted Acid Catalyzed Cyclization of C7 and C8 Dienes in HZSM-5: A Hybrid QM/MM Study and Comparison with C6 Diene Cyclization. J. Phys. Chem. C 2008, 112, 12825-12833 DOI: 10.1021/jp712071k.

(28) Joshi, Y. V.; Bhan, A.; Thomson, K. T. DFT-Based Reaction Pathway Analysis of Hexadiene Cyclization via Carbenium Ion Intermediates: Mechanistic Study of Light Alkane Aromatization Catalysis. J. Phys. Chem. B 2004, 108, 971-980 DOI: 10.1021/jp036205m.

(29) Joshi, Y.; Thomson, K. Embedded cluster (QM/MM) investigation of C6 diene cyclization in HZSM-5. J. Catal. 2005, 230, 440-463 DOI: 10.1016/j.jcat.2004.12.016.

(30) Arstad, B.; Nicholas, J. B.; Haw, J. F. Theoretical study of the methylbenzene side-chain hydrocarbon pool mechanism in methanol to olefin catalysis. J. Am. Chem. Soc. 2004, 126, 2991-3001 DOI: 10.1021/ja035923j.

(31) Wang, C.-M.; Wang, Y.-D.; Xie, Z.-K.; Liu, Z.-P. Methanol to Olefin Conversion on HSAPO-34 Zeolite from Periodic Density Functional Theory Calculations: A Complete Cycle of Side Chain Hydrocarbon Pool Mechanism. J. Phys. Chem. C 2009, 113, 4584-4591 DOI: 10.1021/jp810350x.

(32) Ilias, S.; Bhan, A. The mechanism of aromatic dealkylation in methanol-to-hydrocarbons conversion on H-ZSM-5: What are the aromatic precursors to light olefins? J. Catal. 2014, 311, 6-16 DOI: 10.1016/j.jcat.2013.11.003.

(33) Martinez-Espin, J. S.; Mortén, M.; Janssens, T. V. W.; Svelle, S.; Beato, P.; Olsbye, U. New insights into catalyst deactivation and product distribution of zeolites in the methanol-to-hydrocarbons (MTH) reaction with methanol and dimethyl ether feeds. Catal. Sci. Technol. 2017, 7, 2700-2716 DOI: 10.1039/C7CY00129K. 
(34) Dai, W.; Wu, G.; Li, L.; Guan, N.; Hunger, M. Mechanisms of the Deactivation of SAPO-34 Materials with Different Crystal Sizes Applied as MTO Catalysts. ACS Catal. 2013, 3, 588-596 DOI: $10.1021 / \operatorname{cs} 400007 \mathrm{v}$.

(35) Bjørgen, M.; Olsbye, U.; Kolboe, S. Coke precursor formation and zeolite deactivation: mechanistic insights from hexamethylbenzene conversion. J. Catal. 2003, 215, 30-44 DOI: 10.1016/S00219517(02)00050-7.

(36) Bjørgen, M.; Akyalcin, S.; Olsbye, U.; Benard, S.; Kolboe, S.; Svelle, S. Methanol to hydrocarbons over large cavity zeolites: Toward a unified description of catalyst deactivation and the reaction mechanism. J. Catal. 2010, 275, 170-180 DOI: 10.1016/j.jcat.2010.08.001.

(37) Arora, S. S.; Nieskens, D. L. S.; Malek, A.; Bhan, A. Lifetime improvement in methanol-to-olefins catalysis over chabazite materials by high-pressure $\mathrm{H}_{2}$ co-feeds. Nat. Catal. 2018, 1, 666-672 DOI: 10.1038/s41929-018-0125-2.

(38) Zhao, X.; Li, J.; Tian, P.; Wang, L.; Li, X.; Lin, S.; Guo, X.; Liu, Z. Achieving a super-long lifetime in the zeolite-catalyzed MTO reaction under high pressure: synergistic effect of hydrogen and water. ACS Catal. 2019, 9, 3017-3025 DOI: 10.1021/acscatal.8b04402.

(39) Wristers, J. Strong acid-catalyzed hydrogenation of aromatics. J. Am. Chem. Soc. 1975, 97, 4312-4316 DOI: $10.1021 /$ ja00848a029.

(40) Siria, J. C.; Duran, M.; Lledos, A.; Bertran, J. Acid-catalyzed hydrogenation of olefins. A theoretical study of the hydrogen fluoride and $\mathrm{H} 3 \mathrm{O}+$ catalyzed hydrogenation of ethylene. J. Am. Chem. Soc. 1987, 109, 7623-7629 DOI: 10.1021/ja00259a007.

(41) Senger, S.; Radom, L. Zeolites as Transition-Metal-Free Hydrogenation Catalysts: A Theoretical Mechanistic Study. J. Am. Chem. Soc. 2000, 122, 2613-2620 DOI: 10.1021/ja9935097.

(42) Liu, Y.; Kirchberger, F. M.; Müller, S.; Eder, M.; Tonigold, M.; Sanchez-Sanchez, M.; Lercher, J. A. Critical role of formaldehyde during methanol conversion to hydrocarbons. Nat. Commun. 2019, 10, 1462 DOI: 10.1038/s41467-019-09449-7.

(43) Arora, S. S.; Shi, Z.; Bhan, A. A mechanistic basis for effects of high-pressure $\mathrm{H}_{2}$ co-feeds on methanolto-hydrocarbons catalysis over zeolites. ACS Catal. 2019 DOI: 10.1021/acscatal.9b00969.

(44) Kresse, G.; Hafner, J. Ab initio molecular dynamics for liquid metals. Phys. Rev. B 1993, 47, 558-561 DOI: 10.1103/PhysRevB.47.558.

(45) Kresse, G.; Hafner, J. Ab initio molecular-dynamics simulation of the liquid-metal-amorphoussemiconductor transition in germanium. Phys. Rev. B, Condens. Matter 1994, 49, 14251-14269 DOI: 10.1103/PhysRevB.49.14251.

(46) Kresse, G.; Furthmüller, J. Efficient iterative schemes for ab initio total-energy calculations using a plane-wave basis set. Phys. Rev. B, Condens. Matter 1996, 54, 11169-11186 DOI:

10.1103/physrevb.54.11169.

(47) Kresse, G.; Furthmüller, J. Efficiency of ab-initio total energy calculations for metals and semiconductors using a plane-wave basis set. Comp. Mater. Sci. 1996, 6, 15-50 DOI: 10.1016/09270256(96)00008-0.

(48) Kravchenko, P.; Plaisance, C.; Hibbitts, D. A new computational interface for catalysis. Pre-Print Available rxiv.link/8040737 DOI: 10.26434/chemrxiv.8040737.v3.

(49) Perdew, J. P.; Burke, K.; Ernzerhof, M. Generalized gradient approximation made simple. Phys. Rev. Lett. 1996, 77, 3865-3868 DOI: 10.1103/PhysRevLett.77.3865.

(50) Zhang, Y.; Yang, W. Comment on “Generalized Gradient Approximation Made Simple.”Phys. Rev. Lett. 1998, 80, 890-890 DOI: 10.1103/PhysRevLett.80.890. 
(51) Hammer, B.; Hansen, L. B.; Nørskov, J. K. Improved adsorption energetics within density-functional theory using revised Perdew-Burke-Ernzerhof functionals. Phys. Rev. B 1999, 59, 7413-7421 DOI: 10.1103/PhysRevB.59.7413.

(52) Grimme, S.; Ehrlich, S.; Goerigk, L. Effect of the damping function in dispersion corrected density functional theory. J. Comput. Chem. 2011, 32, 1456-1465 DOI: 10.1002/jcc.21759.

(53) Schröder, H.; Creon, A.; Schwabe, T. Reformulation of the D3(Becke-Johnson) Dispersion Correction without Resorting to Higher than $\mathrm{C}_{6}$ Dispersion Coefficients. J. Chem. Theory Comput. 2015, 11, 31633170 DOI: 10.1021/acs.jctc.5b00400.

(54) Grimme, S.; Antony, J.; Ehrlich, S.; Krieg, H. A consistent and accurate ab initio parametrization of density functional dispersion correction (DFT-D) for the 94 elements H-Pu. J. Chem. Phys. 2010, 132, 154104 DOI: $10.1063 / 1.3382344$.

(55) Monkhorst, H. J.; Pack, J. D. Special points for Brillouin-zone integrations. Phys. Rev. B 1976, 13, 5188-5192 DOI: 10.1103/PhysRevB.13.5188.

(56) van Koningsveld, H. High-temperature (350 K) orthorhombic framework structure of zeolite H-ZSM-5. Acta Crystallogr. B Struct. Sci. 1990, 46, 731-735 DOI: 10.1107/S0108768190007522.

(57) Hoffman, A.; DeLuca, M.; Hibbitts, D. Restructuring of MFI framework zeolite models and their associated artifacts in density functional theory calculations. J. Phys. Chem. C 2019, 123, 6572-6585 DOI: 10.1021/acs.jpcc.8b12230.

(58) Ghorbanpour, A.; Rimer, J. D.; Grabow, L. C. Computational Assessment of the Dominant Factors Governing the Mechanism of Methanol Dehydration over H-ZSM-5 with Heterogeneous Aluminum Distribution. ACS Catal. 2016, 6, 2287-2298 DOI: 10.1021/acscatal.5b02367.

(59) DeLuca, M.; Kravchenko, P.; Hoffman, A.; Hibbitts, D. Mechanism and Kinetics of Methylating $\mathrm{C}_{6}-\mathrm{C}_{12}$ Methylbenzenes with Methanol and Dimethyl Ether in H-MFI Zeolites. ACS Catal. 2019, 9, 6444-6460 DOI: 10.1021/acscatal.9b00650.

(60) Jónsson, H.; Mills, G.; Jacobsen, K. W. Nudged elastic band method for finding minimum energy paths of transitions. In Classical and Quantum Dynamics in Condensed Phase Simulations; Berne, B. J.; Ciccotti, G.; Coker, D. F., Eds.; World Scientific, 1998; pp. 385-404.

(61) Henkelman, G.; Jónsson, H. A dimer method for finding saddle points on high dimensional potential surfaces using only first derivatives. J. Chem. Phys. 1999, 111, 7010-7022 DOI: 10.1063/1.480097.

(62) Martinez-Espin, J. S.; De Wispelaere, K.; Westgård Erichsen, M.; Svelle, S.; Janssens, T. V. W.; Van Speybroeck, V.; Beato, P.; Olsbye, U. Benzene co-reaction with methanol and dimethyl ether over zeolite and zeotype catalysts: Evidence of parallel reaction paths to toluene and diphenylmethane. $J$. Catal. 2017, 349, 136-148 DOI: 10.1016/j.jcat.2017.03.007.

(63) DeLuca, M.; Kravchenko, P.; Hoffman, A.; Hibbitts, D. Mechanism and Kinetics of Methylating $\mathrm{C}_{6}-\mathrm{C}_{12}$ Methylbenzenes with Methanol and Dimethyl Ether in H-MFI Zeolites. ACS Catal. 2019, 9, 6444-6460 DOI: 10.1021/acscatal.9b00650.

(64) Müller, S.; Liu, Y.; Kirchberger, F. M.; Tonigold, M.; Sanchez-Sanchez, M.; Lercher, J. A. Hydrogen Transfer Pathways during Zeolite Catalyzed Methanol Conversion to Hydrocarbons. J. Am. Chem. Soc. 2016, 138, 15994-16003 DOI: 10.1021/jacs.6b09605.

(65) Martínez-Espín, J. S.; De Wispelaere, K.; Janssens, T. V. W.; Svelle, S.; Lillerud, K. P.; Beato, P.; Van Speybroeck, V.; Olsbye, U. Hydrogen Transfer versus Methylation: On the Genesis of Aromatics Formation in the Methanol-To-Hydrocarbons Reaction over H-ZSM-5. ACS Catal. 2017, 7, 5773-5780 DOI: 10.1021/acscatal.7b01643. 
(66) Sun, X.; Mueller, S.; Liu, Y.; Shi, H.; Haller, G. L.; Sanchez-Sanchez, M.; van Veen, A. C.; Lercher, J. A. On reaction pathways in the conversion of methanol to hydrocarbons on HZSM-5. J. Catal. 2014, 317, 185-197 DOI: 10.1016/j.jcat.2014.06.017. 